OPEN ACCESS

Edited by:

Jun $\mathrm{Ma}$,

Sun Yat-sen University Cancer Center

(SYSUCC), China

Reviewed by:

Xu Liu,

Sun Yat-sen University Cancer Center

(SYSUCC), China

Jo Patterson,

City Hospitals Sunderland NHS

Foundation Trust, United Kingdom

*Correspondence:

Lachlan McDowell

lachlan.mcdowel/@petermac.org

Specialty section:

This article was submitted to

Head and Neck Cancer,

a section of the journal

Frontiers in Oncology

Received: 03 January 2020

Accepted: 12 May 2020

Published: 12 June 2020

Citation:

McDowell L, Corry J, Ringash J and Rischin D (2020) Quality of Life,

Toxicity and Unmet Needs in Nasopharyngeal Cancer Survivors.

Front. Oncol. 10:930

doi: 10.3389/fonc.2020.00930

\section{Quality of Life, Toxicity and Unmet Needs in Nasopharyngeal Cancer Survivors}

\author{
Lachlan McDowell ${ }^{1,2 *}$, June Corry ${ }^{3,4}$, Jolie Ringash ${ }^{5}$ and Danny Rischin ${ }^{2,6}$ \\ 1 Department of Radiation Oncology, Peter MacCallum Cancer Centre, Melbourne, VIC, Australia, ${ }^{2}$ Sir Peter MacCallum \\ Department of Oncology, The University of Melbourne, Melbourne, VIC, Australia, ${ }^{3}$ GenesisCare Radiation Oncology, Division \\ Radiation Oncology, St. Vincent's Hospital, Melbourne, VIC, Australia, ${ }^{4}$ Department of Medicine St Vincent's, The University \\ of Melbourne, Melbourne, VIC, Australia, ${ }^{5}$ Department of Radiation Oncology, Princess Margaret Cancer Centre/University of \\ Toronto, Toronto, ON, Canada, ${ }^{6}$ Department of Medical Oncology, Peter MacCallum Cancer Centre, Melbourne, VIC, \\ Australia
}

Concerted research efforts over the last three decades have resulted in improved survival and outcomes for patients diagnosed with nasopharyngeal carcinoma (NPC). The evolution of radiotherapy techniques has facilitated improved dose delivery to target volumes while reducing dose to the surrounding normal tissue, improving both disease control and quality of life (QoL). In parallel, clinical trials focusing on determining the optimal systemic therapy to use in conjunction with radiotherapy have been largely successful, resulting in improved locoregional, and distant control. As a consequence, neoadjuvant chemotherapy (NACT) prior to definitive chemoradiotherapy has recently emerged as the preferred standard for patients with locally advanced NPC. Two of the major challenges in interpreting toxicity and QoL data from the published literature have been the reliance on: (1) clinician rather than patient reported outcomes; and (2) reporting statistical rather than clinical meaningful differences in measures. Despite the lower rates of toxicity that have been achieved with highly conformal radiotherapy techniques, survivors remain at moderate risk of persistent and long-lasting treatment effects, and the development of late radiation toxicities such as hearing loss, cranial neuropathies and cognitive impairment many years after successful treatment can herald a significant decline in QoL. Future approaches to reduce long-term toxicity will rely on: (1) identifying individual patients most likely to benefit from NACT; (2) development of response-adapted radiation strategies following NACT; and (3) anticipated further dose reductions to organs at risk with proton and particle therapy. With increasing numbers of survivors, many in the prime of their adult life, research to identify, and strategies to address the unmet needs of NPC survivors are required. This contemporary review will summarize our current knowledge of long-term toxicity, QoL and unmet needs of this survivorship group.

Keywords: nasopharyngeal carcinoma, radiotherapy, chemotherapy, quality of life, survivorship, toxicity, unmet needs 


\section{INTRODUCTION}

The last three decades have seen considerable progress in the management of patients diagnosed with nasopharyngeal cancer (NPC). While highly conformal radiotherapy (RT) remains the backbone of NPC treatment, the main research focus has been on optimal integration of systemic therapy for both radiosensitization to maximize locoregional control and eradication of micrometastatic disease to address the predominant mode of treatment failure $(1,2)$. The landmark intergroup 0099 study (3) established concomitant and adjuvant cisplatin-based chemotherapy as the standard of care, although much controversy followed, spawning a generation of clinical trials and meta-analyses targeted at identifying those patients most likely to derive benefit from additional systemic treatment (4-8). Flash forward to 2020 and neoadjuvant chemotherapy (NACT) in combination with platinum-based concurrent chemoradiation has become the preferred approach (9-12). In parallel, major technological advances in radiotherapy delivery have allowed for dose escalation to target volumes and reduced normal tissue dosing, resulting in improved disease control (13, 14), toxicity, and QoL (13-19).

While these successes should be celebrated, NPC survivors still harbor a substantial burden of long-term toxicity following successful treatment of their cancer. In endemic populations, the incidence of NPC shows a sharp increase from the third decade, peaking in the sixth decade; in low-risk populations, the incidence increases with age (20). As a consequence, the majority of patients afflicted with NPC are healthy middle-aged adults in the prime of their lives. While the most common and readily apparent radiation-induced toxicities of hearing loss, xerostomia, dysphagia, and hypothyroidism are wellquantified in the literature, survivors face numerous challenges. These include, amongst others, cognitive changes, fatigue, and emotional distress. Although targeted research is lacking, it is likely that NPC survivors will suffer from similar unmet needs to the general head and neck cancer (HNC) population, including workplace rehabilitation, sexual dysfunction and fear of cancer recurrence (21). The focus of this article will be to review our understanding of long-term toxicity, QoL and unmet needs and offer future avenues for targeted research in NPC populations.

\section{TOXICITY AND QUALITY OF LIFE OUTCOMES}

Much of our understanding of toxicities from prospective clinical trials has been reported through the eye of the clinician (Table 1). In contemporary oncology practice, the emphasis has shifted to patient-reported outcome measures (PROMs) as it is reasonably well-established that clinicians may unintentionally under report symptoms $(46,47)$ and their severity $(48,49)$ compared to patients. Only a few of the reported prospective series to date have included PROMs, including QoL assessments (Table 1). The most common PROM collected has been QoL, with the majority of studies using the validated European Organization for Research and Treatment of Cancer quality of life core questionnaire (EORTC QLQ-C30) and the accompanying head and neck module (EORTC QLQ- H\&N35) (Table 1). The QLQC30 contains 30 items which map to a global health status/QoL score (composed of two items), five functional scales, three multiitem symptom scales, and six single symptom items (50); while the 35 items from the QLQ-H\&N35 maps to seven symptom scales and 11 single items (51). Higher scores in the global QoL score and functional scales reflect better QoL or function, while on the symptom scales and items higher scores indicate an increased severity of symptomology. An additional challenge in interpreting QoL data in the current NPC literature has been the reliance on reporting statistically-determined differences rather than clinically meaningful differences, a limitation which has been identified across the oncology trials landscape (52). A commonly used "minimal clinically important difference" in the EORTC modules has been a difference of 10 (53), while Cocks and colleagues have ascribed numerical differences in the components of the EORTC QLQ-C30 as clinically trivial, small, medium or large (54). In the discussion that follows, the clinical difference proposed by Cocks et al. will be used in discussion on the QLQ-C30, and given there are no corresponding thresholds for the QLQ-H\&N35, an estimate of 10 will be used to suggest a clinically meaningful differences in the components of that module.

\section{Prospective Chemotherapy Studies Chemoradiotherapy With or Without Neoadjuvant or Adjuvant Chemotherapy}

The optimal integration of systemic treatment into the management of NPC has driven a large body of prospective clinical trials, both in endemic $(2,4,6,9-12,22-24,27-29$, 31) and non-endemic regions $(3,25,26,30,55,56)$. NACT has emerged as the front runner, based on superior tolerability and compliance, but more importantly, has more consistently shown improvements in survival over concurrent cisplatinbased chemoradiotherapy (CRT) alone $(9,10,22)$. Except where specifically mentioned, toxicity data has been reported from the perspective of the clinician.

The additional increase in toxicity from NACT appears to be manageable and limited to the treatment period, or shortly thereafter, with no differences in clinician-reported late toxicity. As anticipated, NACT results in higher rates of acute hematological toxicity, which in most cases is transient (9$11,23,24)$. While not a consistent finding, some studies report higher rates of nausea and/or vomiting $(9-11,23,24)$ and severe mucositis (24) during the RT phase of treatment following NACT than without it. The data from these studies currently suggest that severe late toxicity ( $\geq$ grade 3 ) is not enhanced with the addition NACT, however longer term reports are needed to confirm this finding (Table 2) $(9,12,22-24)$. One of the concerns about combining cisplatin induction chemotherapy with concurrent cisplatin and radiation is the potential for increased toxicity related to the cumulative dose of cisplatin e.g., peripheral neuropathy. Indeed a higher rate of grade 1-4 peripheral neuropathy was reported in the gemcitabine-cisplatin induction study (9). In this trial there was also a higher incidence of acute nephrotoxic events. No difference in ototoxicity was 
TABLE 1 | Selected NPC studies reporting long-term quality of life and toxicity and the instruments used.

\begin{tabular}{|c|c|c|c|c|c|c|}
\hline Study & No. & Treatment & RT & QoL assessment & \multicolumn{2}{|c|}{ Toxicity measurement } \\
\hline $\begin{array}{l}\text { Sun et al. (10) } \\
\text { Li et al. (22) }\end{array}$ & 241 & $\mathrm{HDC}-\mathrm{CRT} \pm \mathrm{TPF}$ induction & IMRT 100\% & Not yet reported & $\begin{array}{l}\text { Acute - CTCAE v } 3.0 \\
\text { Late - } \\
\text { RTOG }\end{array}$ & No \\
\hline Zhang (9) & 480 & $\mathrm{HDC}-\mathrm{CRT} \pm \mathrm{GC}$ induction & IMRT 100\% & No & $\begin{array}{l}\text { Acute - } \\
\text { CTCAE v4.0 } \\
\text { Late - } \\
\text { RTOG }\end{array}$ & No \\
\hline Hui (12) & 65 & LDC-CRT \pm DP induction & $3 \mathrm{D}$ & $\begin{array}{l}\text { EORTC QLQ-C30 and } \\
\text { H\&N35 }\end{array}$ & $\begin{array}{l}\text { Acute - } \\
\text { CTCAE v2.0 } \\
\text { Late } \\
\text { RTOG }\end{array}$ & $\begin{array}{l}\text { EORTC } \\
\text { QLQ-H\&N35 }\end{array}$ \\
\hline Hong (24) & 479 & $\begin{array}{l}\text { LDC-CRT } \pm \text { MEPFL } \\
\text { induction }\end{array}$ & $\begin{array}{l}\text { IMRT } 61 \% \\
\text { 3D 39\% }\end{array}$ & No & $\begin{array}{l}\text { Acute - } \\
\text { CTCAE v3.0 } \\
\text { Late } \\
\text { RTOG }\end{array}$ & No \\
\hline Fountzilas (25) & 141 & LDC-CRT \pm CET induction & 3D 100\% & No & $\begin{array}{l}\text { Acute - } \\
\text { CTCAE v3.0 } \\
\text { RTOG - } \\
\text { Late } \\
\text { RTOG }\end{array}$ & No \\
\hline Al-Sarraf et al. (3) & 193 & $\begin{array}{l}\text { RT alone vs. HDC-CRT }+ \\
\text { PF }\end{array}$ & $2 \mathrm{D}$ & No & SWOG & No \\
\hline Wee et al. (4) & 221 & $\begin{array}{l}\text { RT alone vs. HDC-CRT + } \\
\text { PF }\end{array}$ & $2 \mathrm{D}$ & No & Acute-RTOG & No \\
\hline Lee et al. $(28,29)$ & 348 & $\begin{array}{l}\text { RT alone vs. HDC-CRT }+ \\
\text { PF }\end{array}$ & $\begin{array}{l}\text { 2D } 41 \% \\
\text { Mix } 8 \% \\
\text { Conformal 61\% }\end{array}$ & No & $\begin{array}{l}\text { RTOG } \\
\text { Chemo toxicities - WHO }\end{array}$ & No \\
\hline Rossi et al. (30) & 229 & $\mathrm{RT}$ alone $\pm \mathrm{VAC}$ & $2 \mathrm{D}$ & No & Method/System NR & No \\
\hline Chi et al. (31) & 157 & $\mathrm{RT}$ alone $\pm \mathrm{PF}$ & $2 \mathrm{D}$ & No & Method/System NR & No \\
\hline \multicolumn{7}{|c|}{ OTHER PROSPECTIVE CHEMOTHERAPY STUDIES } \\
\hline Chen, Li $(5,22)$ & 230 & $\begin{array}{l}\text { RT alone vs LDC-CRT } \\
\text { (stage II only) }\end{array}$ & $2 \mathrm{D}$ & No & $\begin{array}{l}\text { Acute-CTCAE } \\
\text { Late-RTOG }\end{array}$ & No \\
\hline Lee (2) & 109 & $\begin{array}{l}\text { Weekly vs. triweekly CRT (+ } \\
\text { Adjuvant) }\end{array}$ & $\begin{array}{l}\text { IMRT 74\% } \\
\text { 2D-CRT 16\% }\end{array}$ & $\begin{array}{l}\text { EORTC QLQ-C30 and } \\
\text { H\&N35 }\end{array}$ & Acute-RTOG & $\begin{array}{l}\text { EORTC } \\
\text { QLQ-H\&N35 }\end{array}$ \\
\hline \multicolumn{7}{|c|}{ PROSPECTIVE INTENSITY-MODULATED vS. 2D/3D RADIOTHERAPY STUDIES } \\
\hline Kam et al. (32) & 60 & IMRT vs. 2D & $\begin{array}{l}\text { IMRT 50\% } \\
\text { 2D 50\% }\end{array}$ & No & RTOG & No \\
\hline Pow et al. (33) & 46 & IMRT vs. 2D & $\begin{array}{l}\text { IMRT 52\% } \\
\text { 2D 48\% }\end{array}$ & $\begin{array}{l}\text { EORTC QLQ-C30 and } \\
\text { H\&N35 }\end{array}$ & No & $\begin{array}{l}\text { EORTC } \\
\text { QLQ-H\&N35 }\end{array}$ \\
\hline Peng et al. (14) & 616 & IMRT vs. 2D & $\begin{array}{l}\text { IMRT 50\% } \\
\text { 2D 50\% }\end{array}$ & No & CTCAE v3.0 & No \\
\hline
\end{tabular}


TABLE 1 | Continued

\begin{tabular}{|c|c|c|c|c|c|c|}
\hline Study & No. & Treatment & RT & QoL assessment & \multicolumn{2}{|c|}{ Toxicity measurement } \\
\hline \multicolumn{7}{|c|}{ OTHER ENDEMIC STUDIES } \\
\hline Fang et al. (35) & 68 & CRT 100\% & VMAT 100\% & $\begin{array}{l}\text { EORTC QLQ-C30 and } \\
\text { H\&N35 }\end{array}$ & CTCAE v4.03 & $\begin{array}{l}\text { EORTC } \\
\text { QLQ-H\&N35 }\end{array}$ \\
\hline Pan et al. (37) & 106 & CRT $48 \%$ & $\begin{array}{l}\text { IMRT 56\% 2D } \\
44 \%\end{array}$ & $\begin{array}{l}\text { EORTC QLQ-C30 and } \\
\text { H\&N35 }\end{array}$ & No & $\begin{array}{l}\text { EORTC } \\
\text { QLQ-H\&N35 }\end{array}$ \\
\hline Tsai et al. (19) & 242 & CRT 66\% & $\begin{array}{l}\text { IMRT 41\% } \\
\text { Non-IMRT 59\% }\end{array}$ & EORTC QLQ-C30 & CTCAE v4.0 & No \\
\hline Wu et al. (38) & 192 & CRT 23\% & $\begin{array}{l}\text { 2D 34\% } \\
\text { Co-60 66\% }\end{array}$ & Chinese SF-36 & No & No \\
\hline Lee et al. (13) & 1593 & - & $\begin{array}{l}\text { IMRT 28\% } \\
\text { 3D 45\% } \\
\text { 2D 27\% }\end{array}$ & No & $\begin{array}{l}\text { RTOG } \\
\text { CTCAE v3.0 }\end{array}$ & No \\
\hline Talmi et al. (43) & 28 & CRT 64\% & $2 \mathrm{D}$ & (UW)-QoL & No & $\begin{array}{l}\text { (UW)-QoL includes } \\
\text { patient reported } \\
\text { toxicity }\end{array}$ \\
\hline Ghiggia et al. (44) & 21 & CRT 100\% & NS & $\begin{array}{l}\text { EORTC QLQ-C30 and } \\
\text { H\&N35 }\end{array}$ & RTOG & $\begin{array}{l}\text { EORTC QLQ- } \\
\text { H\&N35 }\end{array}$ \\
\hline Yee et al. (45) & 82 & CRT 77\% & $\begin{array}{l}\text { 3D } 43 \% \\
\text { 2D 57\% }\end{array}$ & No & RTOG & No \\
\hline
\end{tabular}

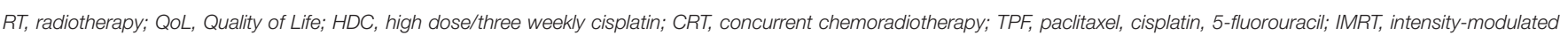

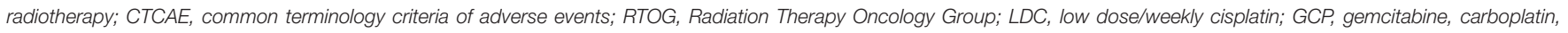

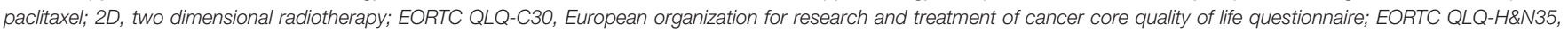

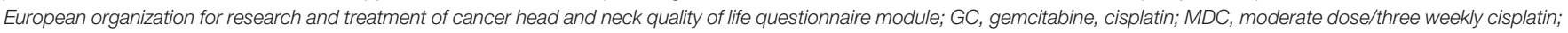



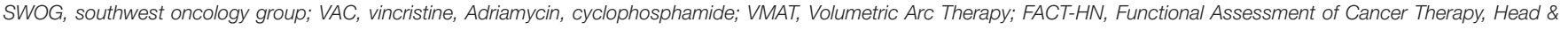

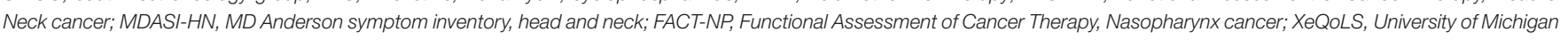
Xerostomia-Related Quality of Life scale; (UW)-QoL, University of Washington Quality of Life Questionnaire.

reported, though it is possible that clinician reported late cisplatin side effects may underestimate the incidence.

Only two of these prospective NACT studies have reported QoL (Table 3) (12, 23). The larger, from Singapore, randomized
172 patients between concurrent weekly cisplatin $\left(40 \mathrm{mg} / \mathrm{m}^{2}\right)$ with or without induction therapy using gemcitabine, carboplatin and paclitaxel (23). Almost all patients were treated with intensity-modulated radiotherapy (IMRT; 98\%). The QLQ-C30 
TABLE 2 | Selected studies reporting clinician-rated late toxicities (grade $\geq 3$ ).

\begin{tabular}{|c|c|c|c|c|c|c|c|c|c|c|c|}
\hline Study & No. & Treatment & RT & FU & $\begin{array}{l}\text { Any } \\
\geq G 3\end{array}$ & Xerostomia & Dysphagia & Hearing & TLN & $\mathrm{CN}$ & Notes \\
\hline \multicolumn{12}{|c|}{ PROSPECTIVE CONCURRENT CRT \pm NEO/ADJUVANT CHEMOTHERAPY } \\
\hline Li et al. (22) & 480 & $\begin{array}{l}\text { HDC-CRT } \pm \text { TPF } \\
\text { induction }\end{array}$ & IMRT & $5.9 y$ & $\begin{array}{l}9 \% \\
\text { (9 vs. 8\%) }\end{array}$ & $\begin{array}{c}1 \% \\
(0.8 \text { vs. } 2 \%)\end{array}$ & $N R$ & $6 \%$ (6 vs. 6\%) & $\begin{array}{c}0 \% \\
\text { (0 vs. 0\%) }\end{array}$ & $\begin{array}{c}1 \% \\
(2 \text { vs. } 1 \%)\end{array}$ & No difference between arms \\
\hline Tan et al. (23) & 172 & $\begin{array}{l}\mathrm{LDC}-\mathrm{CRT} \pm \mathrm{GCP} \\
\text { induction }\end{array}$ & $\begin{array}{l}\text { IMRT 98\% } \\
\text { 2D 4\% }\end{array}$ & $3.4 \mathrm{y}$ & NR & $8 \%$ (11 vs. $5 \mathrm{NS}$ ) & NR & NR & NR & NR & No difference between arms \\
\hline Zhang et al. (9) & 480 & $\begin{array}{l}\mathrm{HDC}-\mathrm{CRT} \pm \mathrm{GC} \\
\text { induction }\end{array}$ & IMRT & $3.6 \mathrm{y}$ & $10 \%$ (11 vs. $9 \%)$ & $3 \%$ (2 vs. $3 \%)$ & $N R$ & $6 \%$ (7 vs. $5 \%)$ & $\begin{array}{c}0.4 \% \\
\text { (1 vs. } 0 \%)\end{array}$ & $\begin{array}{c}0.8 \% \\
(0.8 \text { vs. } 0.8 \%)\end{array}$ & $\begin{array}{l}\text { No difference between arms, } \\
\text { except higher G1/2 } \\
\text { peripheral neuropathy in } \\
\text { induction arm }\end{array}$ \\
\hline Hui et al. (12) & 65 & $\begin{array}{l}\mathrm{LDC}-\mathrm{CRT} \pm \mathrm{DP} \\
\text { induction }\end{array}$ & $3 \mathrm{D}$ & 3.0y FU & $\begin{array}{l}57 \% \\
\text { (65 vs. } 50 \%)\end{array}$ & $N R$ & $\begin{array}{c}1.6 \% \\
\text { (4 vs. } 0 \%)\end{array}$ & $\begin{array}{c}10 \% \\
\text { (12 vs. } 9 \%, N S)\end{array}$ & NR & NR & $\begin{array}{l}\text { No difference in late toxicity } \\
\text { between arms }\end{array}$ \\
\hline Hong et al. (24) & 479 & $\begin{array}{l}\mathrm{LDC}-\mathrm{CRT} \pm \mathrm{MEPFL} \\
\text { induction }\end{array}$ & $\begin{array}{l}\text { IMRT 61\% } \\
\text { 3D 39\% }\end{array}$ & $6.0 y$ & $\begin{array}{l}15 \% \text { (13 vs. } 17 \% \\
\text { NS) }\end{array}$ & $2 \%$ (2 vs. $2 \%)$ & $6 \%$ (4 vs. $7 \%$ ) & NR & NR & NR & No difference between arms \\
\hline Chen et al. $(6,27)$ & 508 & $\begin{array}{l}\text { LDC-CRT alone vs. } \\
\text { LDC-CRT + PF }\end{array}$ & $\begin{array}{l}\text { IMRT 42\% } \\
\text { 3D 5\% } \\
\text { 2D 53\% }\end{array}$ & $5.7 y$ & $\begin{array}{l}24 \% \\
(21 \text { vs. } 27 \%, \\
p=0.14)\end{array}$ & $\begin{array}{c}7 \% \\
\text { (6 vs. } 7 \%)\end{array}$ & $N R$ & $\begin{array}{c}12 \% \\
(11 \text { vs. } 13)\end{array}$ & $\begin{array}{c}3 \% \\
\text { (3 vs. } 3 \%)\end{array}$ & $\begin{array}{c}2 \% \\
(2 \text { vs. } 2 \%)\end{array}$ & $\begin{array}{l}\text { No difference in late toxicity } \\
\text { between arms }\end{array}$ \\
\hline \multicolumn{12}{|c|}{ PROSPECTIVE RT ALONE \pm CONCURRENT WITH ADJUVANT STUDIES } \\
\hline Lee et al. (28) & 172 & $\begin{array}{l}\text { RT alone vs. HDC-CRT } \\
+\mathrm{PF}\end{array}$ & $\begin{array}{l}2 \mathrm{D} 41 \% \\
\text { Mix } 8 \% \\
\text { Conf } \\
61 \%\end{array}$ & $\begin{array}{c}10.7 \\
(\min 10 y \mathrm{FU})\end{array}$ & 52 vs. $47 \%, p=0.20)$ & NR & $\begin{array}{c}1.7 \% \\
\text { (2 vs. } 1 \%)\end{array}$ & $\begin{array}{c}24 \% \\
\text { (27 vs. } 20 \%)\end{array}$ & $\begin{array}{c}1 \% \\
\text { (2 vs. } 0.6 \%)\end{array}$ & $\begin{array}{c}6 \% \\
\text { (7 vs. } 5 \%\end{array}$ & $\begin{array}{l}\text { Chemotherapy did not } \\
\text { increase late toxicity }\end{array}$ \\
\hline \multicolumn{12}{|c|}{ OTHER PROSPECTIVE CHEMOTHERAPY STUDIES } \\
\hline $\begin{array}{l}\text { Chen, Li et al. } \\
(5,22)\end{array}$ & 230 & RT alone vs LDC-CRT & 2D & $10.4 \mathrm{y}$ & $\begin{array}{l}26 \% \text { vs. } 35 \% \\
\text { (NS) }\end{array}$ & 0 vs. $0 \%$ & NR & 15 vs. $13 \%$ & 10 vs. $6 \%$ & 11 vs. 12 & $\begin{array}{l}\text { No difference in late toxicity } \\
\text { between 3D and IMRT }\end{array}$ \\
\hline \multicolumn{12}{|c|}{ PROSPECTIVE INTENSITY-MODULATED vs. 2D/3D RADIOTHERAPY STUDIES } \\
\hline Kam et al. (32) & 60 & IMRT vs. 2D & $\begin{array}{l}\text { IMRT 50\% } \\
\text { 2D 50\% }\end{array}$ & $\begin{array}{c}1 \mathrm{y} \\
\text { assessment }\end{array}$ & NR & 39 vs. $82 \%{ }^{*}$ & NR & NR & NR & NR & \\
\hline Peng et al. (14) & 616 & IMRT vs. 2D & $\begin{array}{l}\text { IMRT 50\% 3D } \\
50 \%\end{array}$ & $3.5 \mathrm{y}$ & NR & $\begin{array}{c}0 \text { vs. } 2(\geq G 3) \\
10 \text { vs. } 29 \text { ( } \geq G 2)\end{array}$ & NR & $\begin{array}{l}26 \text { vs. } 84 \% \\
(p<0.001)\end{array}$ & $\begin{array}{l}21 \text { vs. } 13 \% \\
(p=0.01)\end{array}$ & $\begin{array}{c}4 \text { vs. } 9 \\
(p=0.02)\end{array}$ & $\begin{array}{l}\text { Comparison of toxicity } \\
\text { (grades) not clear in late } \\
\text { analysis; significant } \\
\text { differences across multiple } \\
\text { late toxicities and additional } \\
\text { for trismus and neck fibrosis }\end{array}$ \\
\hline \multicolumn{12}{|c|}{ OTHER ENDEMIC STUDIES } \\
\hline Fang et al. (35) & 68 & $100 \%$ CRT & VMAT $100 \%$ & $\begin{array}{c}4 y \\
\text { cumulative } \\
\text { incidence }\end{array}$ & $3 \%$ & $0 \%$ & NR & $3 \%$ & $0 \%$ & $0 \%$ & Single arm VMAT report \\
\hline Tsai et al. (19) & 242 & CRT 66\% & $\begin{array}{l}\text { IMRT 41\% } \\
\text { Non- } \\
\text { IMRT 59\% }\end{array}$ & $\begin{array}{l}\text { EORTC } \\
\text { QLQ-C30 }\end{array}$ & CTCAE v 4.0 & & & & & & \\
\hline Lee et al. (13) & 1593 & & $\begin{array}{l}\text { IMRT 28\% } \\
\text { 3D } 45 \% \\
\text { 2D 27\% }\end{array}$ & $\begin{array}{c}6.8 \mathrm{y} \\
(0.2-18.4 \mathrm{y})\end{array}$ & NR & $N R$ & $N R$ & $\begin{array}{l}\text { IMRT 17\% } \\
\text { 3D 19\% } \\
\text { 2D 10\% }\end{array}$ & $\begin{array}{l}\text { IMRT } 1 \% \\
\text { 3D 2\% } \\
\text { 2D 3\% }\end{array}$ & $\begin{array}{l}\text { IMRT 2\% } \\
\text { 3D 2\% } \\
\text { 2D 5\% }\end{array}$ & \\
\hline
\end{tabular}




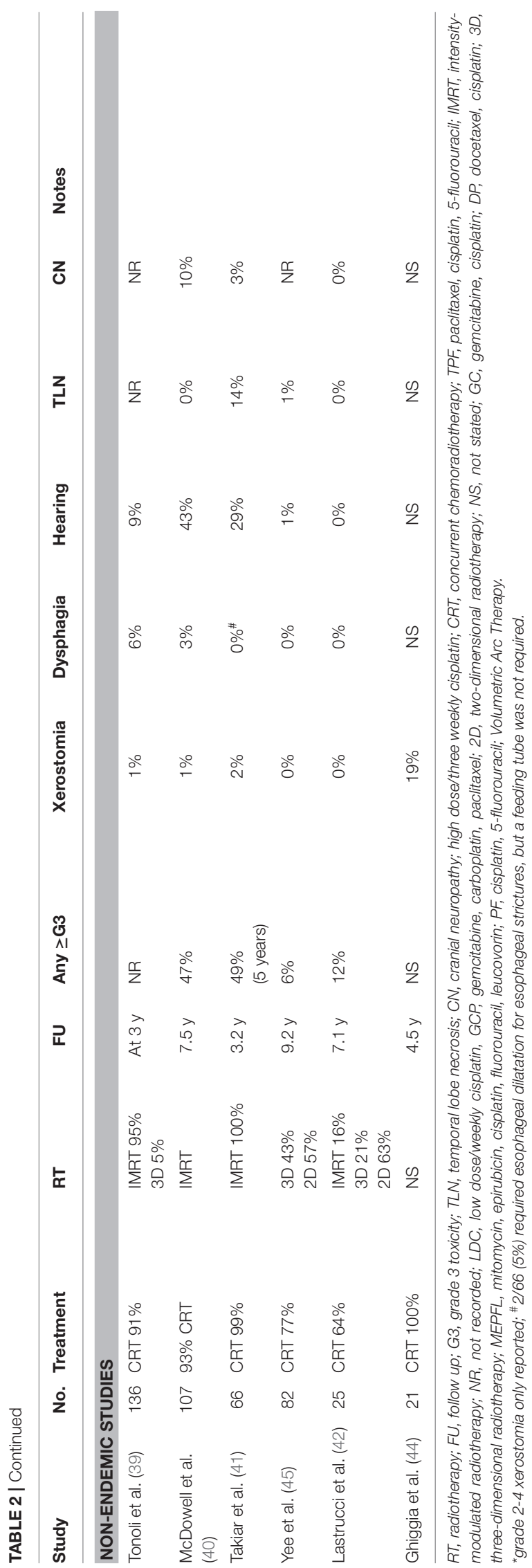

and QLQ-H\&N35 modules were collected at baseline, day 8 of cycle 2 in the NACT arm, during CRT (week 4), at the end of CRT, and at 3, 12, 24, and 60 months after treatment. Global QoL was similar between the two arms at all corresponding time points. Transient (and clinically small) differences favoring the CRT alone arm were observed in the EORTC QLQ-C30 dyspnoea (24.3 vs. $15.3 ; p=0.014$ ) and diarrhea (15.2 vs. 9.3; $p$ $=0.018$ ) scales. Somewhat counterintuitively patients in the CRT alone arm reported higher scores for pain, swallowing problems and pain killer use during treatment, and reported worse social contact at 3 months. It is unclear if these differences were purely statistical as the size of the difference was not included in the report. In all cases, these differences were isolated to the acute treatment and recovery period and differences resolved with follow up. In the smaller study of 65 patients reported by Hui et al., patients were randomized to CRT (with 3D-RT) with or without cisplatin-docetaxel induction (12). In both arms, declines were seen in the QLQ-C30 and QLQ-H\&N35 scores compared to baseline in the acute treatment period, which gradually returned to baseline over time, and differences in global QoL scores did not differ between the arms at the measured times points. A deterioration in physical functioning scores was more marked in those receiving NACT during the treatment period (mean change in scores -42.9 vs. $-27.7, p=0.0499$ ), although this resolved with further follow up. In the symptom scales, appetite (mean change 18.6 vs. $-5.3 ; p=0.023$ ) and constipation (mean change 24.5 vs. $-3.8 ; p=0.0075$ ) scores were worse in the NACT arm compared to the CRT alone arm at 4 weeks after CRT, but there were no differences at subsequent follow up. Differences by arm in the QLQ-H\&N35 were seen only in the nutritional supplement score at the 24 month assessment only (mean change score, 10.0 vs. $-23.5 ; p=0.025$ ), favoring the concurrent only arm.

In the single study to prospectively evaluate the addition of adjuvant chemotherapy (PF) following definitive chemoradiotherapy, Chen et al. found that severe late toxicity was similar between arms, with the exception of peripheral neuropathy, which was worse in the adjuvant arm, but the overall rate of severe toxicity ( $\geq$ grade $3 / 4$ ) was low ( 2 vs. $0.4 \%, p=0.05$ ) $(6,27)$.

Taken together, the published literature to date suggests that NACT or adjuvant chemotherapy is well-tolerated with manageable and time-limited toxicity compared to standard cisplatin-based CRT.

\section{Prospective Studies of Chemotherapy Compared to Radiotherapy Alone}

Radiotherapy as a single modality treatment is generally reserved for stage I disease (T1N0). While adding concurrent chemotherapy significantly improved survival in stage II patients (Chinese 1992 staging system) treated with 2D RT $(5,22)$, its necessity is under question in the IMRT era (57-59). In the prospective study by Chen et al., all patients were treated with $2 \mathrm{D}$ and the experimental arm consisted of weekly $(30 \mathrm{mg} / \mathrm{m} 2)$ cisplatin $(5,22)$. Patients in the CRT arm had a higher incidence of any severe acute toxicity ( $\geq$ grade 3, 64 vs. $40 \%, p<0.001$ ), and a significant increase was observed for hematological toxicity, nausea and vomiting ( 9 vs. $0 \%, p=0.001$ ), and mucositis (46 
TABLE 3 | Selected NPC studies reporting Quality of Life outcomes.

\begin{tabular}{|c|c|c|c|c|c|c|}
\hline Study & No. & Treatment & $\mathbf{R T}$ & FU & QoL & QoL findings \\
\hline \multicolumn{7}{|c|}{ PROSPECTIVE CONCURRENT CRT \pm NEO/ADJUVANT CHEMOTHERAPY } \\
\hline Tan et al. (23) & 172 & $\begin{array}{l}\text { LDC-CRT } \pm \text { GCP } \\
\text { induction }\end{array}$ & $\begin{array}{l}\text { IMRT 98\% } \\
\text { 2D 4\% }\end{array}$ & $3.4 \mathrm{y}$ & $\begin{array}{l}\text { EORTC QLQ-C30 } \\
\text { and H\&N35 }\end{array}$ & $\begin{array}{l}\text { No difference in global QoL, GCP arm worse } \\
\text { dyspnea and diarrhea during CRT; } \\
\text { H\&N35, worse pain swallowing use of pain } \\
\text { killers in GCP during CRT and for social } \\
\text { contact at } 3 \mathrm{~m}\end{array}$ \\
\hline Hui et al. (12) & 65 & $\begin{array}{l}\mathrm{LDC}-\mathrm{CRT} \pm \mathrm{DP} \\
\text { induction }\end{array}$ & 3D & - & $\begin{array}{l}\text { EORTC QLQ-C30 } \\
\text { and H\&N35 }\end{array}$ & $\begin{array}{l}\text { No difference in global QoL; Physical } \\
\text { functioning more deterioration, appetite and } \\
\text { constipation worse at } 4 \text { months in induction } \\
\text { arm; all resolved with longer follow up; Only } \\
\text { difference in H\&N35 was nutritional supplement } \\
\text { use in induction arm at } 24 \mathrm{~m} \text { post treatment }\end{array}$ \\
\hline \multicolumn{7}{|c|}{ OTHER PROSPECTIVE CHEMOTHERAPY STUDIES } \\
\hline Lee et al. (2) & 109 & $\begin{array}{l}\text { LDC vs. HDC CRT } \\
\text { (+ adjuvant) }\end{array}$ & $\begin{array}{l}\text { IMRT 74\% } \\
\text { 2D 16\% }\end{array}$ & Last QoL at $12 \mathrm{~m}$ & $\begin{array}{l}\text { EORTC QLQ-C30 } \\
\text { and H\&N35 }\end{array}$ & $\begin{array}{l}\text { Patients on weekly regimen showed better PF, } \\
\text { EF and SF than the triweekly group and } \\
\text { reported less appetite loss } 3 \text { weeks post } \\
\text { treatment; } \\
\text { Worse speech, social contact and sticky saliva } \\
\text { in triweekly group; } \\
\text { No differences at } 3 \text { and } 12 \mathrm{~m} \text { post treatment } \\
\text { except dry mouth }(3 \mathrm{~m}) \text { and SF }(12 \mathrm{~m}) \text { post CRT }\end{array}$ \\
\hline Pow et al. (33) & 46 & IMRT vs. 2D & $\begin{array}{l}\text { IMRT 52\% } \\
\text { 2D 48\% }\end{array}$ & $\begin{array}{l}\text { Longitudinal } \\
\text { assessment } \\
\text { baseline, 2, } 612 \mathrm{~m} \\
\text { post RT }\end{array}$ & $\begin{array}{l}\text { EORTC QLQ-C30 } \\
\text { and H\&N35 }\end{array}$ & $\begin{array}{l}\text { No difference between IMRT and CRT global } \\
\text { QoL at any point; at } 12 \mathrm{~m} \text { both global QoL } \\
\text { scores = 64; No differences between baseline } \\
\text { and } 12 \mathrm{~m} \text { post treatment, except global QoL, } \\
\text { RF, EF were higher and insomnia lower than } \\
\text { baseline in both groups; most of the domains } \\
\text { showed improvement from } 2 \text { to } 12 \text { months. } \\
\text { Role-physical, bodily pain, and physical } \\
\text { function domains better in IMRT cohort }\end{array}$ \\
\hline \multicolumn{7}{|c|}{ OTHER ENDEMIC STUDIES } \\
\hline $\begin{array}{l}\text { Fang et al. } \\
\text { (17) }\end{array}$ & 237 & $28 \% \mathrm{CRT}$ & $\begin{array}{l}\text { Conventional 64\% } \\
\text { (2D 26\%, 2D + 3D } \\
\text { boost 38\%) } \\
\text { Conformal 36\% } \\
\text { (3D 14\%, } \\
\text { IMRT 22\% }\end{array}$ & - & $\begin{array}{l}\text { EORTC QLQ-C30 } \\
\text { and H\&N35 }\end{array}$ & $\begin{array}{l}\text { Global QoL higher in conformal group (63 v51, } \\
p<0.01 \text { ) } \\
\text { Conformal outcomes better across multiple } \\
\text { points including PF, EF CF, SF functioning } \\
\text { domains; 6/12 QLQ-C30 symptom scales and } \\
12 / 13 \text { H\&N35 symptom scales } \\
\text { On UVA, QoL better in higher educated, higher } \\
\text { income, employed, conformal technique and } \\
\text { less medical comorbidities }\end{array}$ \\
\hline $\begin{array}{l}\text { Fang et al. } \\
\text { (34) }\end{array}$ & 203 & CRT 55\% & $\begin{array}{l}\text { IMRT 46\% } \\
\text { 3D 54\% }\end{array}$ & $\begin{array}{l}\text { Longitduinal } \\
\text { Baseline, during } \\
\text { RT and } 3,12 \text {, and } \\
24 \mathrm{~m} \text { post } \mathrm{RT}\end{array}$ & $\begin{array}{l}\text { EORTC QLQ-C30 } \\
\text { and H\&N35 }\end{array}$ & $\begin{array}{l}12 \text { and } 24 \text { months global QoL } 61 \text { and } 62 \text {; IMRT } \\
\text { better global QoL, fatigue, taste, dry mouth and } \\
\text { feeling ill at } 3 \mathrm{~m} \text {, improved with time; No other } \\
\text { medical, sociodemographic factors predicted } \\
\text { worse QoL; General trend of deterioration } \\
\text { followed by recover in most QoL scales from } \\
\text { baseline to during, and then after RT }\end{array}$ \\
\hline $\begin{array}{l}\text { Fang et al. } \\
\text { (35) }\end{array}$ & 68 & CRT $100 \%$ & VMAT $100 \%$ & $\begin{array}{l}\text { Longitudinal: } \\
\text { baseline, during } \\
\text { RT, } 3 \mathrm{~m}, 12 \mathrm{~m}\end{array}$ & $\begin{array}{l}\text { EORTC QLQ-C30 } \\
\text { and H\&N35 }\end{array}$ & $\begin{array}{l}12 \text { months global QoL mean score } 78 \text {; } \\
\text { Generally maximal decline in most scales from } \\
\text { baseline to mid treatment with improvement } \\
\text { thereafter; Chemotherapy or medical or } \\
\text { sociodemographics factors did not predict QoL } \\
\text { score }\end{array}$ \\
\hline $\begin{array}{l}\text { Hong et al. } \\
\text { (36) }\end{array}$ & 216 & CRT 98\% & $\begin{array}{l}\text { IMRT 75\% } \\
\text { Conformal 25\% }\end{array}$ & 4.4 y (mean) & EORTC QLQ-C30 & $\begin{array}{l}\text { Mean global QoL 74; no difference by time } \\
\text { since treatment; factors associated with better } \\
\text { QoL were older age, higher education, higher } \\
\text { anxiety and depression scores, worse dry } \\
\text { mouth and fatigue, and higher disease stage }\end{array}$ \\
\hline
\end{tabular}


TABLE 3 | Continued

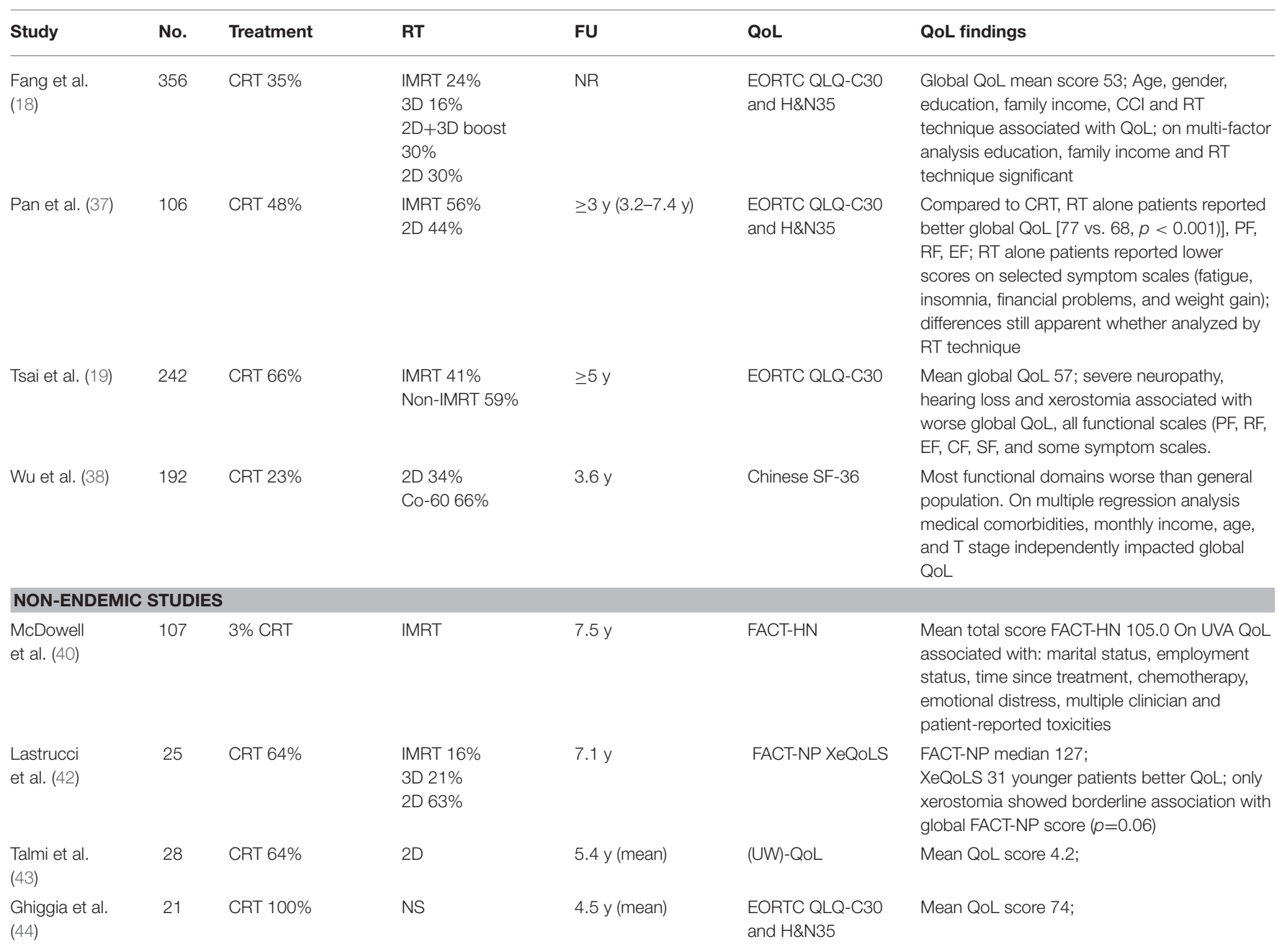

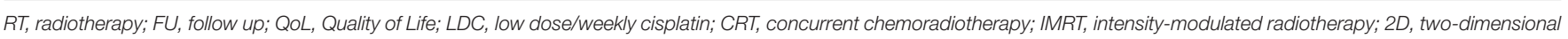



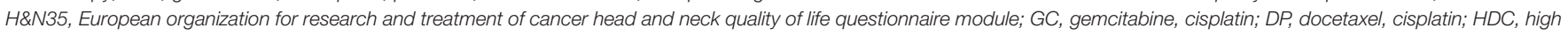

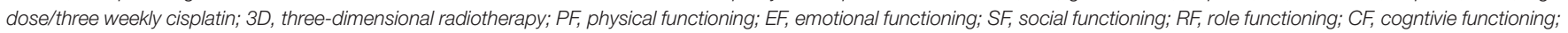


Xerostomia-Related Quality of Life scale; (UW)-QoL, University of Washington Quality of Life Questionnaire. y, year.

vs. $33 \%, p=0.04)$. At the 10 years follow up, there was no significant differences in late toxicity (RT 26 vs. CRT 35\%). In a cross-sectional study which analyzed QoL outcomes in in stage II patients who had been treated with either RT alone or CRT, and a follow up time of at least 3 years, the authors reported that the addition of chemotherapy resulted in a detrimental impact on global QoL and a number of the functional and symptom scales from the QLQ-C30 and QLQ-H\&N35 (37). When the analysis was restricted to patients treated only with IMRT, the authors reported a similar finding. In this study, the reported differences across the QLQ-C30 scores for the full and IMRT cohorts, which were in favor of the RT alone group would be considered small, with the exception of the financial problems item which would be considered of medium difference. In the IMRT alone cohort, there were some statistical differences favoring the RT alone group in the QLQ-H\&N35 items, but only the less sexuality, nutritional supplements and weight gain items were in excess of ten points difference.

In the landmark studies which randomized patients to radiotherapy alone with or without concomitant and adjuvant chemotherapy, there was a predictable transient increase in severe hematological toxicity $(3-5,28,29)$, mucositis $(4,5,28)$, and nausea/vomiting $(3-5,28)$. Of these studies, the Hong Kong Nasopharyngeal Cancer Study Group NPC-9901 study published 10 -year toxicity outcomes $(28,29)$. They reported no differences with respect to grade 3 or higher toxicities between the CRT and RT arms ( 52 vs. $47 \%, p=0.20$ ); and the majority of severe toxicity in both arms was attributable to ototoxicity, which was surprisingly similar between the arms (CRT 37 vs. RT alone $27 \%$, $p=0.19$ ). One interesting finding from this study was that severe 
late toxicity was higher in the chemotherapy arm at 3 years, a difference which dissipated with longer follow up. Numerically there was a shorter average latency time to developing a severe toxicity in the chemotherapy group which did not reach statistical significance ( 4.2 years vs. 4.7 years, $p=0.40$ ). However, this latency period is quite informative when interpreting late toxicity data from other clinical trials, where follow up may not extend beyond 5 years.

\section{Prospective Concurrent Studies-Three Weekly or Weekly Chemotherapy?}

The optimal schedule of concurrent cisplatin in the definitive setting remains an unanswered question across the breadth of HNC subsites, including NPC. This question has only been addressed prospectively in NPC in a phase II study from the Korean Cancer Study Group (2). The study found no differences between clinician reported toxicity in the acute phase of treatment. While global QoL was not significantly different at any point during the study, patients treated on the weekly arm showed improved physical $(p=0.039)$, emotional $(p=0.019)$, and social functioning $(\mathrm{p}=0.008)$ compared to the triweekly group at 3 weeks after completion of CRT, but these differences diminished at subsequent follow up. On the symptom scales (QLQ-C30 and H\&N35), the triweekly group reported more appetite loss $(p=0.006)$ and problems with speech $(p=0.003)$, social contact $(p-0.043)$ and sticky saliva $(p=0.019)$ than the weekly group. These differences again largely resolved (dry mouth had a persistent difference at 3 months) with longer follow up. Although both chemotherapy and RT for HNC can cause significant hearing loss and dysfunction, this is not captured in either of the EORTC modules. While non-NPC HNC series have reported worse ototoxicity with high dose (three weekly) compared to low dose (weekly) $(60,61)$, in this study it was not captured in the PROMs and only acute treatment-related toxicity was recorded; with only two patients reported as developing hearing loss, one from each arm.

\section{Meta-Analysis of Chemotherapy in NPC Trials-MAC-NPC}

The Meta-Analysis of Chemotherapy in Nasopharynx Carcinoma (MAC-NPC) collaborative group included an analysis of acute and late toxicity differences with the addition of chemotherapy to RT alone (7). This analysis predates the most recent practicechanging NACT studies. Mirroring results from the included studies, the addition of chemotherapy resulted in a significant increase in acute hematological toxicity and nausea/vomiting and mucositis. In addition, acute ototoxicity and more profound weight loss were also significantly higher with chemotherapy. While most of the individual studies did not identify an increase in late toxicities, the pooled analysis reported significantly higher rates of long-term hearing deficits $(p=0.00068)$ and a borderline increased risk of a cranial neuropathy $(p=0.052)$.

\section{Prospective Radiotherapy Specific Studies Impact of Radiotherapy Technique Changes}

The introduction of IMRT revolutionized NPC treatment, allowing both improved target volume coverage and reduced dose to adjacent organs at risk (OARs). At least three randomized controlled trials have addressed the benefit of IMRT compared to historical RT techniques, including 2D and 3D RT (Tables 1-3) $(14,32,33)$. Peng et al. reported on the largest RCT, with 616 patients randomized to either IMRT or 2D RT (14). Local control favored the IMRT arm, with a corresponding reduction in the incidence of both acute toxicities, including xerostomia ( $\geq$ Grade $2 ; 57$ vs. $28 \%, p<0.001$ ) and hearing loss (89 vs. $47 \%, p<0.001$ ) and late toxicities (median follow up 3.5 years), including temporal lobe necrosis (TLN; 21 vs. $13 \%, p=0.01$ ), cranial neuropathy ( 9 vs. $4 \%, p=0.02$ ), trismus (14 vs. $3 \%$ $p<0.001$ ), neck fibrosis (11 vs. $2 \%, p<0.001$ ), xerostomia ( $\geq \mathrm{G} 1$ 99 vs. $40 \%, p<0.001$ ), and hearing loss ( 85 vs. $26 \%, p<0.001$ ). There was no QoL assessment in this study.

Two smaller prospective randomized studies specifically focused on the benefit of IMRT over 2D treatment with respect to salivary gland function $(32,33)$. Kam et al. reported lower rates of severe (clinician-reported) xerostomia in the IMRT arm (39 vs. $82 \%, p<0.001$ ), with corresponding higher rates of measured salivary flow (32). A xerostomia PROM was included, with a trend to improvement in the IMRT group. Pow et al. also reported that functional salivary flow showed significantly better recovery in the IMRT cohort (33). It is important to note that the mean doses delivered to the parotid in this study was higher than is generally used (where possible) in contemporary practice, with a mean ipsilateral and contralateral parotid dose of 42 (range 31-51Gy) and 41Gy (range 33-42 Gy), respectively. Using the EORTC QoL modules and the SF-36 questionnaire, IMRT-treated patients reported improved role-physical, bodily pain, and physical function scores at 1 year (all $p<0.05$ ). Both groups reported dry mouth and sticky saliva, but better recovery of these xerostomia-type symptoms were observed in the IMRT cohort.

In a series form Taiwan, Fang et al. reported a longitudinal, but non-randomized comparison of 203 NPC patients, with any stage (I-IV), treated with either IMRT $(N=110)$ or $3 \mathrm{D}$ RT $(N=93)$ (34). In this study, allocation was on the basis of clinician preference or linac availability. The EORTC QLQC30 and QLQ-H\&N35 modules were assessed at baseline, mid treatment (week 4) and 3, 12, and 24 months after completion of treatment. The majority of patients completed all assessments (71.4\%). As expected, maximal deterioration was seen during treatment which improved with subsequent follow up, and the benefit of IMRT over 3D-RT appeared to be limited to the early recovery period. The IMRT arm showed clinically meaningful better outcomes at 3 months for global QoL (56 vs. 44), fatigue ( 29 vs. 39 ), taste ( 22 vs. 35 ), dry mouth ( 49 vs. 59 ) and feeling ill ( 25 vs. 36$)$; these differences diminished with ongoing follow up. From the same institution, a longer follow up of more than 5 years (median follow up: non-IMRT group 8.5 years, IMRT group 6.4 years) reported better long term toxicity experience for the IMRT cohort relative to the 3D-RT group across multiple domains of the QLQ-C30 and QLQ-H\&N35, including moderate differences in global QoL, cognitive and social functioning, and fatigue on the QLQ-C30; and large differences in speech and dry mouth and moderate differences in most of the QLQ-H\&N35 scales (16). 
The experience and use of volumetric arc therapy (VMAT), is also increasing, and although there have been no direct clinical comparisons between standard IMRT and VMAT, planning studies have shown enhanced sparing of the parotids, brain stem and spinal cord is possible (62).

\section{Adaptive Radiotherapy}

Adaptive strategies in HNC offer the promise of reducing the degree of normal tissue irradiation based on early tumor response. In a replanning series by Yang et al., the outcomes of 129 IMRT-treated patients were compared. All patients were advised to have a repeat simulation scan either before the 15th fraction $(12 \%)$, the 25 th fraction $(61 \%)$ or both $(27 \%)$. However, only 86 were replanned (67\%), while 43 (33\%) refused, and consequently received the same plan throughout the treatment course (63). Two-year locoregional control favored the replanned arm ( 97.2 vs. $92.4 \%, p=0.040)$, with similar survival ( 89.8 vs. $82.2 \%, p=0.475)$. A significant benefit favoring the replanning group was reported on components of both the QLQ-C30 (global QoL, role and social functional scales and the dyspnea, appetite, constipation and diarrhea symptom scales) and the QLQ-H\&N35 (speech, social contact, and teeth, mouth opening, dry mouth and sticky saliva) modules. Most of the differences were appreciable during the treatment and the early recovery period, with a diminishing difference with further follow up; for example, the differences in global QoL at 1 month post treatment (61 vs. 48), were of a medium sized clinical difference, while the difference at 12 months ( 82 vs. 78 ) is considered a trivial to small clinical difference (54). There was an imbalance in global QoL at baseline, favoring the non-replanning group (77 vs. 68), and while the non-replanned group returned to baseline with time, the replanned group actually demonstrated a positive shift from baseline, so the difference may be more significant than the 12-months results suggest. The diminishing difference with longer follow up was noticeable across most scales, with the exception of sticky saliva (24 vs. 17) and dry mouth (33 vs. 25), which both showed an ongoing higher symptom burden in the non-replanned group. While this is a potentially appealing strategy to reduce toxicity, adaptive treatment and replanning is resource-intensive. Further research regarding efficacy and efficient implementation is needed before adaptive treatment is likely to become routine.

\section{Post-induction Response-Adapted Strategies}

Adapting radiation dose and target volumes based on NACT response offers yet another strategy for reducing long-term toxicity and potentially improving QoL $(64,65)$. While better rates of local control have been achieved with a dose to the primary GTV $\geq 66.5 \mathrm{~Gy}$ (1), this may not be required for controlling microscopic disease in the setting of a complete response to NACT, when assessed by metabolic, radiological and clinical means. Yang et al. reported the results of a prospective randomized study including 212 patients with target volumes based on either pre (Arm A) or post induction (Arm B) imaging following a cisplatin doublet (paclitaxel or 5-FU) (64). Target definitions and doses used in this protocol are outlined in Table 4. Both the primary GTV (45 vs. $26 \mathrm{~cm}^{3}, p<0.001$ ) and high dose CTV (367 vs. $305 \mathrm{~cm}^{3}, p=0.045$ ) were smaller in Arm B. There were no differences in disease outcomes between these arms, either in the initial report (median follow up 35 months) (64), or in the subsequent 4 years update presented at ASTRO in 2019 (surprisingly, the presented data numerically favored the post-IC group) (66). There were no differences observed in acute clinician-rated toxicity, but lower rates of dry mouth were reported at 2 years in Arm B (grade 0-1/2-3: 68\%/32\% Arm A vs. $76 \% / 24 \%$; Arm B; $p=0.042$ ). With respect to QoL, measured by the EORTC QLQ-C30, statistically significant differences in cognitive function (76 vs. 65) and lower pain scores (76 vs. 67) were reported, with the estimated clinical impact of these differences considered medium and small, respectively (54). In both arms the entire nasopharynx with a margin and the entire pre induction disease was treated to $64 \mathrm{~Gy} / 33 \#$, and the usual intermediate risk area was included to $54 \mathrm{~Gy} / 33 \#$, irrespective of response. Other series have also reported outcomes with full dose (70 Gy) to the post induction volumes and reduced doses (60 Gy) to the pre induction tumor volume $(67,68)$. Future strategies aimed at reducing toxicity will need to implement a strategy of reducing wide field treatment of the critical structures of the base of skull and brain to almost curative doses of radiation, capitalizing on how best to assess treatment response.

Although large scale clinical trials are lacking, there is further suggestion in the literature that doses to gross disease below 70 Gy may provide adequate locoregional control in some patients. In a phase II study from the Peter MacCallum Center, 35 patients were treated with three cycles of induction epirubicin, cisplatin and 5-fluorouracil, followed by cisplatinbased chemoradiation (56). Radiation therapy was delivered with $2 \mathrm{D}$ planning to $60 \mathrm{~Gy}$ over 6 weeks at standard fractionation. After three cycles, 30/35 (86\%) had a documented clinical and radiological (MRI/CT) response (2 complete, 28 partial). At a median follow up of 43 months only two patients had a locoregional relapse; one regional relapse in the elective nodal region $(50 \mathrm{~Gy})$ and one local (and concomitant distant) failure where the upper level of the field was limited to $54 \mathrm{~Gy}$ to remain under optic chiasm tolerance. In the previously mentioned retrospective study by $\mathrm{Ng}$ et al. a significant difference in local and regional control was reported when at least $66.5 \mathrm{~Gy}$ was delivered to the respective GTVs using IMRT (1). However, less than half $(41.5 \%)$ received induction chemotherapy, and GTVs were contoured according to pre induction volumes. Other series have analyzed control rates in patients who failed to complete the prescribed course of treatment. Wang et al. performed a propensity match analysis comparing 234 patients completing the prescribed $70 \mathrm{~Gy}$ course of radiotherapy with 32 patients who did not complete treatment due to severe acute toxicities (69). In the entire cohort, 163/266 (61.5\%) received NACT. The median dose in the non-completion group was $63.6 \mathrm{~Gy}$ (range 53-67.8 Gy) and the authors reported no difference in 5 -years locoregional failure free survival (LRFS) between those receiving the reduced dose or the prescribed dose (92.5 vs. $91.7 \%$; $p=0.863$ ). Furthermore, radiation dose was not a significant variable in a univariate analysis of prognostic factors for LRFS. A smaller series $(n=19)$ by Lu et al. concluded that patients who received a minimum of $54 \mathrm{~Gy}$ had a 5 -years LRFS of $100 \%$ (70). 
TABLE 4 | Target volumes used in the study by Yang et al. (64).

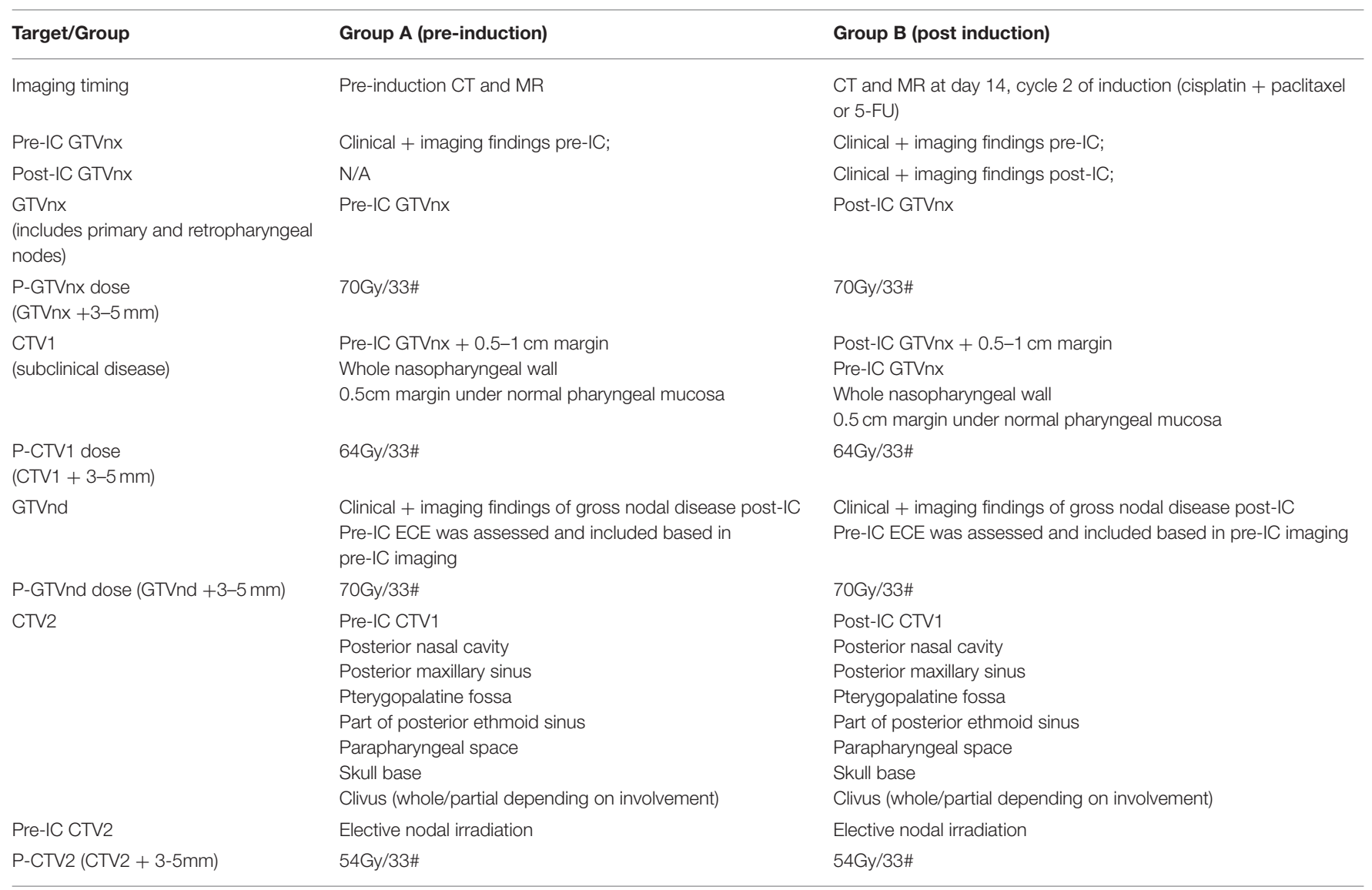

CT, computed tomography; MR, magnetic resonance imaging; 5-FU, 5-Fluorouracil; IC-induction chemotherapy; GTVnx, nasopharynx gross tumor volume; P-GTV-nx, high dose primary planning target volume; CTV, clinical planning volume; P-CTV -planning target volume based on CTV; GTVnd, nodal gross tumor volume; P-GTVnd, high dose nodal planning target volume.

However, this was a subset of only nine patients, and further details reported that there were no local or regional relapses in the 5-years follow up period when a minimum dose of $60 \mathrm{~Gy}$ was given. While interesting and potentially hypothesis generating, retrospective series reporting on patients failing to complete treatment are limited by bias, small numbers and heterogeneity in chemotherapy regimens.

Dose reductions, particularly to the base of skull region will likely offer a more beneficial strategy to reduce the burden of toxicity in NPC survivors than other proposed approaches, such as a reduction of elective nodal volumes. Under the auspices of a clinical trial, dose and volume de-escalation based on NACT response, incorporating clinical, radiological (both structural and metabolic) and biological response (including EBV-titres) may provide a real opportunity to further improve outcomes for these patients.

\section{Reducing Elective Nodal Volumes}

Two regions that may be spared from routine elective irradiation include the submandibular (Ib) station and the low neck (Level $\mathrm{IV} / \mathrm{Vb}$ ). Level $\mathrm{Ib}$ involvement at diagnosis or as a site of subsequent failure is an infrequent occurrence, although the risk may be higher in the following situations: [1] where a level II node measures $>20 \mathrm{~mm}$ or demonstrates radiological extracapsular extension; [2] where there are bilateral cervical LNs (N2); or [3] if the primary tumor extends into the oropharynx (71). While this is appealing strategy to reduce toxicity, the clinical impact is less clear. The main rationale for omitting level $\mathrm{Ib}$ is to reduce xerostomia, however Zhang et al. failed to demonstrate a statistically significant reduction in the frequency of grade 2 or higher xerostomia in 904 low risk patients whether they had bilateral Ib sparing, unilateral Ib sparing, or inclusion of bilateral Ib (10 vs. 14 vs. $18 \%, p=0.06)$. In optimizing dose reduction to the submandibular gland, the tradeoff may be an increase in dose to other xerostomia-critical organs such as the parotid or oral cavity (72). While a dose constraint of $<39 \mathrm{~Gy}$ has been proposed for the submandibular gland, based on improvements in stimulated and unstimulated salivary gland flow in non-NPC cohorts, it can be challenging to meet this when there is gross disease at level 2 , and mean doses $\geq 50$ Gy are generally expected (73). Although there have been studies looking at omitting the low neck in selected case of NPC, there is little comparative data at present to suggest improved clinical outcomes with this approach $(58,74)$. 


\section{Particle Therapy}

Particle therapy offers the potential to reduce doses to OARs in HNC treatment $(75,76)$ and planning studies in NPC have shown improved metrics, with respect to both target coverage and OAR doses (77-80). However, clinical reports on efficacy and toxicity are limited $(79,81,82)$. In a small retrospective series of 10 patients treated with intensity-modulated proton therapy (IMPT) from MD Anderson, Lewis et al. reported no late grade 3 toxicities (79); and grade 1 and 2 xerostomia were reported in 6 and 1 patient/s, respectively. The median follow up was only 24.5 months, shorter than the average latency time to development of severe toxicity (29). A case matched series from that institution (10 IMPT and 20 IMRT cases), reported lower rates of gastrostomy tube insertion during treatment in patients treated with IMPT, 65 vs. $20 \%(p=0.020)(80)$. Results from a prospective phase II study from Massachusetts General Hospital are awaited, as to date this has only been presented in abstract form (81). In the abstract report, grade 3 or higher late hearing and weight loss was reported in 29 and $38 \%$ of patients, respectively, and $1 / 23$ patients remained PEG dependent at 12 months.

\section{Target Volume and Treatment Planning Heterogeneity} While the above studies have highlighted a number of different strategies focusing on reducing toxicity, two large sources of heterogeneity in the treatment planning process which may significantly impact toxicity are variations in target volume contouring and what constitutes an acceptable radiotherapy treatment plan (83-85). While the pioneering work of Peters et al. eloquently demonstrated the detrimental impact of poorly compliant radiotherapy treatment plans on long-term survival in HNC patients (86), a less obvious sin is that of overcontouring, which while resulting in locoregional control, may labor survivors with unnecessary morbidity. The findings from Peters et al. have spawned a generation of international consensus guidelines for $\mathrm{HNC}$ contouring and dose prioritization, including recommendations for $\operatorname{NPC}(87,88)$, and while they may have reduced the variation to some degree, they have not completely mitigated it (85). In addition, an increasing recognition of the importance of HNC case volume and expertise $(89,90)$ and the value of peer-review in clinical practice $(91,92)$ will have hopefully further reduced this variation. However, with the recent number of immunotherapy trials opening, there has been a concerning trend in the number of trials failing to include a comprehensive radiotherapy quality assurance program (93). Clinician variability in both contouring and the variations accepted in radiotherapy treatment plans are arguably the most significant factors in determining long-term treatment toxicity, reducing the benefit of other toxicity-sparing measures mentioned above, and further ways to ensure the delivery of optimal treatment plans is required.

\section{Toxicity and Quality of Life Reports From Non-endemic Areas}

The majority of studies reporting toxicity and QoL arise from NPC endemic regions, with a few studies reporting from nonendemic regions (Tables 1-3).
A prospective study of 136 patients treated at 12 Italian centers from 2008 to 2010 included patients mostly treated with IMRT (95\%) and focused on clinician-reported toxicity (39). At 3 years follow up, hearing loss was the most common grade 3 toxicity (8.6\%), followed by dysphagia (5.5\%), periodontal disease $(4.3 \%)$ and xerostomia (1.3\%). The frequency of the most common grade 2 toxicities were xerostomia $(23.4 \%)$, hearing loss $(12.9 \%)$, and dysphagia (12.3\%).

One of the more comprehensive studies from a nonendemic region comes from a cross-sectional study conducted at the Princess Margaret Hospital in Toronto (40). This study included clinician and patient-reported toxicity, a QoL measure, audiometry testing, basal endocrine screening (thyroid and pituitary) and a cognitive and neurobehavioral assessment. There were 107 patients enrolled at a median follow up time of 7.5 years (4.1-11.1 years) following IMRT. The highest rated patient-reported toxicities/problems from the MDASI-HN were dry mouth, mucous, swallowing/chewing, memory and teeth and gums. The prevalence of $\geq$ grade 3 toxicities was $47 \%(50 / 107)$; mostly hearing loss (43\%), with a much smaller prevalence $(11 \%)$ of non-hearing grade 3 toxicities, including 11 patients $(10 \%)$ with $\geq$ grade 3 cranial neuropathies. One-quarter of patients reported moderate to high levels of fatigue. On univariate analysis, a number of factors correlated with worse global QoL, including social factors (living, marital and employment status), treatment factors (time since treatment, use of chemotherapy), emotional distress (depression or anxiety) and multiple clinician graded toxicities (hearing, ear discharge, dysphagia, trismus, aspiration, and cranial neuropathy). When correlating patient-reported toxicity, every item of the MDASI-HN PRO correlated with QoL, indicating that the presence of any significant symptom has capacity to adversely impact QoL.

In a series of IMRT-treated patients with T4 disease, the MD Anderson Cancer Center reported long term toxicity in 66 patients treated with a mean follow up of 66 months (1124 months) (41). The actuarial rate of Grade 3 toxicity was $36 \%$ at 3 years and $49 \%$ at 5 years. Hearing problems were the most frequent severe toxicity, but the rate of severe toxicity not attributable to hearing at 3 and 5 years was 23 and $33 \%$, respectively. Cranial or peripheral neurotoxicity was reported in $15 / 66$ patients $(23 \%)$ including two patients with grade 3 radiation-induced optic neuropathy; the remaining cases (13/15) had grade 2 toxicity. Radiological TLN was demonstrated in nine patients (14\%), two with reported cognitive impairment; cognitive impairment was reported in an additional two patients without TLN.

\section{Factors Impacting on Long-Term Quality of Life}

Factors which have been associated with QoL are summarized in Table 5. The studies show some conflicting findings, likely stemming from differences in patient populations, social constructs (particularly where sociodemographic factors are concerned) and variations in statistical methods to report predictive factors, including single or multi-factor models. 
TABLE 5 | Selected studies reporting factors associated with patient-reported quality of life.

\begin{tabular}{|c|c|c|c|c|c|c|}
\hline \multirow[t]{2}{*}{ Factor/Study } & \multicolumn{5}{|l|}{ Endemic } & \multirow{2}{*}{$\begin{array}{l}\text { Non-endemic } \\
\text { McDowell et al. (40) }\end{array}$} \\
\hline & Fang et al. (17) & Fang et al. (18) & Hong et al. (36) & Wu et al. (38) & Tsai et al. (19) & \\
\hline \multicolumn{7}{|l|}{ SOCIAL FACTORS } \\
\hline Sex & No & Yes (1F only) & No & Yes (UVA only) & Yes (1F only) & No \\
\hline Age & No & $\begin{array}{l}\text { Yes (older better; } \\
1 \mathrm{~F} \text { only) }\end{array}$ & $\begin{array}{l}\text { Yes (younger } \\
\text { worse) }\end{array}$ & $\begin{array}{l}\text { Yes (older better } \\
\text { on MVA and UVA) }\end{array}$ & No & No \\
\hline Living status & NR & NR & NR & NR & NR & $\begin{array}{l}\text { Yes (living with others } \\
\text { better than isolated) }\end{array}$ \\
\hline Education level & $\begin{array}{l}\text { Yes (higher education } \\
>12 y \text { better on UVA, } \\
\text { not MVA }(p=0.08)\end{array}$ & $\begin{array}{l}\text { Yes (higher } \\
\text { educated better, } \\
\text { both } 1 \mathrm{~F} \text { and MF) }\end{array}$ & $\begin{array}{l}\text { Yes (higher } \\
\text { educated better) }\end{array}$ & No & $\begin{array}{l}\text { Yes (both } 1 \mathrm{~F} \text { and } \\
\text { MF) }\end{array}$ & No \\
\hline $\begin{array}{l}\text { Employment } \\
\text { status }\end{array}$ & $\begin{array}{l}\text { Yes (employed better } \\
\text { on UVA, not MVA) }\end{array}$ & NR & NR & No & NR & $\begin{array}{l}\text { Yes } \\
\text { (homemaker/caregive } \\
\text { and disability leave } \\
\text { worse than full time } \\
\text { employment) }\end{array}$ \\
\hline Depression & NR & NR & $\begin{array}{l}\text { Yes (higher worse } \\
\text { QoL) }\end{array}$ & NR & NR & $\begin{array}{l}\text { Yes (higher worse } \\
\text { QoL) }\end{array}$ \\
\hline Anxiety & NR & NR & $\begin{array}{l}\text { Yes (higher worse } \\
\text { QoL) }\end{array}$ & NR & NR & $\begin{array}{l}\text { Yes (higher worse } \\
\text { QoL) }\end{array}$ \\
\hline Recurrence Worry & NR & NR & No & NR & NR & NR \\
\hline \multicolumn{7}{|l|}{ TUMOR FACTORS } \\
\hline T-category & NR & NR & NR & $\begin{array}{l}\text { Yes (lower T better } \\
\text { QoL on UVA and } \\
\text { MVA) }\end{array}$ & NR & NR \\
\hline $\mathrm{N}$-category & NR & NR & NR & No & NR & NR \\
\hline Stage & No & No & $\begin{array}{l}\text { Yes (higher stage } \\
\text { worse QoL) }\end{array}$ & No & No & $\begin{array}{l}\text { No (stage IVB worse } \\
\text { than stage I) }\end{array}$ \\
\hline \multicolumn{7}{|c|}{ TREATMENT FACTORS } \\
\hline $\begin{array}{l}\text { Time since } \\
\text { treatment }\end{array}$ & NR & No & No & No & $\begin{array}{l}\text { Yes (both } 1 \mathrm{~F} \text { and } \\
\text { MF) }\end{array}$ & $\begin{array}{l}\text { Yes (better with } \\
\text { longer FU) }\end{array}$ \\
\hline Chemotherapy & No & No & NR & No & $\begin{array}{l}\text { Borderline on } 1 \mathrm{~F} \\
(p=0.058)\end{array}$ & $\begin{array}{l}\text { Yes (none better than } \\
\text { any) }\end{array}$ \\
\hline Radiation tech & $\begin{array}{l}\text { Yes (3D/IMRT better } \\
\text { than 2D on both UVA } \\
\text { and MVA) }\end{array}$ & $\begin{array}{l}\text { Yes (both } 1 F \text { and } \\
\text { MF; IMRT better) }\end{array}$ & NR & No & $\begin{array}{l}\text { Yes (both } 1 \mathrm{~F} \text { and } \\
\text { MF) }\end{array}$ & N/A (all IMRT) \\
\hline
\end{tabular}


TABLE 5 | Continued

\begin{tabular}{|c|c|c|c|c|c|c|}
\hline \multirow[t]{2}{*}{ Factor/Study } & \multicolumn{5}{|l|}{ Endemic } & \multirow{2}{*}{$\begin{array}{l}\text { Non-endemic } \\
\text { McDowell et al. (40) }\end{array}$} \\
\hline & Fang et al. (17) & Fang et al. (18) & Hong et al. (36) & Wu et al. (38) & Tsai et al. (19) & \\
\hline \multicolumn{7}{|c|}{ TOXICITY FACTORS } \\
\hline Clinician-reported & NR & NR & $\begin{array}{l}{ }^{*} \text { xerostomia and } \\
\text { fatigue }\end{array}$ & NR & $\begin{array}{l}\text { Neuropathy, } \\
\text { hearing, } \\
\text { xerostomia (both } \\
1 \mathrm{~F} \text { and MF); } \\
\text { Dysphagia and } \\
\text { neck fibrosis (1F) }\end{array}$ & $\begin{array}{l}\text { Hearing, ear } \\
\text { discharge, } \\
\text { dysphagia, trismus, } \\
\text { dysarthria, aspiration, } \\
\text { cranial neuropathy }\end{array}$ \\
\hline $\begin{array}{l}\text { Patient-reported } \\
\text { toxicity }\end{array}$ & NR & NR & NR & NR & & $\begin{array}{l}\text { All items MDASI-HN } \\
\text { correlated with QoL }\end{array}$ \\
\hline
\end{tabular}

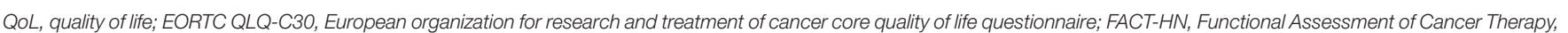




as yes/no.

\section{Sociodemographic Factors \\ Age}

In some studies worse QoL has been observed in younger patients (42) while others have shown the contrary $(18,36,38)$, and some have shown no association (40).

\section{Sex}

In some series, male survivors have been reported to have improved long-term QoL $(18,19)$, while others have reported that sex does not influence QoL $(17,36,40)$.

\section{Marital status/living status}

Marital status has not be shown to influence global QoL in studies from endemic regions (17-19, 38). In contrast, the aforementioned series from Toronto reported that divorced or separated patients, but not single or widowed patients scored lower global QoL scores compared to cohabitating (married/common law/other) patients (40).

\section{Education, and employment status/income}

Education status $(17-19,36)$, employment status $(17,40,94)$ and income have all been associated with improved global QoL in NPC cohorts $(17,18,38)$.

\section{Patient Factors Medical factors}

Where included, the burden of medical comorbidities has been linked with worse QoL in NPC survivors $(17,18,38)$.

\section{Emotional distress}

Similar to series reporting for other HNCs, higher rates of anxiety and depression correlate with worse global QoL (95-98), in both endemic and non-endemic NPC series (36, 40, 44, 99-101). A complex interplay and association exist between QoL, toxicity and emotional distress, and a higher burden of toxicity has been shown to correlate with worse emotional distress and QoL in NPC survivors $(40,100)$.

\section{Other}

QoL is a complex construct which may be affected by many different factors that may or may not be captured in PROMs currently used in clinical research, including consultation satisfaction, optimism and worry (102).

\section{Treatment Factors Chemotherapy}

The actual impact of chemotherapy on long-term QoL is difficult to quantify, given most prospective NPC studies have not included QoL assessments. The two NACT trials which included QoL assessments suggest that the addition of NACT may have a transient, but not long-lasting impact on QoL $(12,23)$. Based on the cross-sectional series included in Table 5, impact was either absent $(17,18,38)$ or identified only in single factor models $(19,40)$ without accounting for confounding variables such as stage. In a study limited to patients with stage II NPC, it was reported that the addition of concomitant chemotherapy resulted in worse long term global QoL (54). When isolating these results to IMRT-treated patients only, the reported difference in EORTC QLQ-C30 global QoL score was 86 vs. 79, a difference which could be considered small or clinically insignificant (54).

\section{Radiotherapy technique}

Although not all studies have shown a significant improvement in QoL with IMRT (33), most studies have reported a positive impact (15-19). Adaptive strategies, including treatment replanning (63) and response-adaptive target volume delineation following induction chemotherapy are discussed above and have also been reported to improve QoL (64-66).

\section{Toxicity Factors}

Table 5 presents studies reporting the impact of individual toxicities on long-term QoL. Most have used clinician-rated toxicity and found a significant correlation between some, but not all the measured toxicities $(19,36,40)$. PRO measures, however may be more reliable. In a study using the MDASI-HN tool, the mean symptom burden showed strong correlation with global QoL (FACT-HN total, $r=0.76, p<0.001$ ), and every item of 
the MDASI-HN inventory showed a very strong correlation with global QoL on univariate analysis, suggesting that the presence of any severe toxicity can adversely impact QoL (40).

\section{Treatment Toxicity-Where Can We Further Our Understanding?}

Following many years of clinical trials data there is still much to understand. This article has highlighted past reliance on clinician-reported toxicities and the presence of "severe" or grade 3 or higher toxicity. This approach does not discriminate the varying effects of individual toxicities on the patient (not all grade 3 toxicities will impact patients to the same degree), and may fail to direct enough attention to the significant impact that grade 1-2 toxicities can have on the long-term well-being of the patient. In terms of relying on clinician reports, it is wellappreciated that clinicians may under report both symptoms $(46,47)$ and their severity $(48,49)$ compared to patients. In the series reported above by McDowell et al. xerostomia was ranked "severe" (grade 3 CTCAE) by only $1 \%$ of clinicians, yet $49 \%$ of patients rated their problems with dry mouth in the severe range ( $\geq 7$ on the MDASI-HN item) (40). This large discrepancy is only one example of where potentially we can further our understanding of toxicity, and future research should focus on what matters to patients. In addition to the wellestablished toxicities, such as xerostomia, dysphagia and hearing loss, it is worth highlighting additional toxicities requiring further research, such as neurotoxicity, endocrine dysfunction and fatigue.

\section{Neurotoxicity \\ Cranial neuropathies}

Cranial neuropathies can be catastrophic for the NPC survivor, heralding a significant decline in QoL $(19,40)$. The average latency period is between four and seven years after treatment, but shorter or longer intervals are reported (103-106), with few effective options to reverse or stabilize symptoms (107). In the IMRT era, radiation induced cranial neuropathies have been reported in up to $14 \%$ of patients (Table 6). Although any of the cranial nerves may be affected, the hypoglossal nerve is most frequently involved, owing to its tortuous course near the high dose region of the nasopharynx and upper neck $(40,106)$. A hypoglossal nerve palsy can remain stable or demonstrate insidious progression, rendering a patient dependent on a feeding tube. In the largest series, reported by Chow et al., T-stage and diabetes mellitus as well as the dose to the hypoglossal nerve (D1cc: $<74$ Gy $2.4 \%$ vs. $\geq 74$ Gy $20.8 \%, p<0.001$ ) were all predictors for a hypoglossal nerve palsy (106). This highlights the importance of optimizing treatment plans, ensuring dose homogeneity around the base of skull and reducing hotspots, despite these being deemed as acceptable by current ICRU guidelines. Chemotherapy may be a factor: in the MACNPC analysis, there was a borderline increased risk of cranial neuropathies with the addition of chemotherapy to RT alone $(11.4 \%$ vs. $8.7 \%, \mathrm{HR}=1.35(1.00-1.82), p=0.052)(7)$. The potential impact of NACT is unknown.

\section{Cognitive and neurobehavioral toxicity}

TLN is a well-recognized toxicity following NPC treatment (Table 2). IMRT-treated patients appear to have a significantly reduced risk of developing TLN (13). TLN has generally been reported as either symptomatic TLN, where the patient has a constellation of symptoms including reduced cognitive function with radiologic temporal lobe changes, or asymptomatic/radiologic TLN, where there is imaging evidence of necrosis in the temporal lobes, but the patient appears to be functioning normally from the perspective of the clinician. Prior to IMRT, TLN was shown to correlate with poorer cognitive function $(99,108)$, however this association has not been clearly demonstrated in IMRT-treated patients, although there are only few reports available $(40,109-112)$. In a cohort of 102 patients with a mean age and time since treatment of 56 and 7.5 years, respectively, McDowell et al. reported $32 \%$ of patents scoring in the neurocognitively impaired range (112). Asymptomatic TLN was reported in $22 \%$ of patients, which did not correlate with either objective (MoCA) or subjective (MDASI-HN memory problems item) cognitive assessment. In this series, frontal dysfunction was also high when self-rated by either the patient or their family member. Clinically significant rates of dysfunction in the domains of apathy, disinhibition and executive functioning were reported by 48,35 , and $39 \%$ of patients and 66,53 , and $56 \%$ of family members (who were reporting on the patients function), respectively. This study highlights the importance of measuring what matters; TLN has been used as a surrogate marker for radiation-induced damage to the brain and the designation of whether a patient is "symptomatic" has been based on a crude clinician assessment. However, directly measuring the functional impacts of our treatments, such as cognitive and frontal dysfunction provides more relevant and patient-focussed information, which can be used to counsel and consent patients. Cisplatin has also been implicated in cognitive dysfunction following cancer treatment (113), although the individual impacts of concurrent and neo/adjuvant chemotherapy and RT on cognition in NPC treatment have not been well-quantified in the literature.

\section{Endocrine Dysfunction Hypothyroidism}

Compared to other HNC populations, NPC patients appear to be particularly vulnerable to developing primary hypothyroidism following neck irradiation (114). In IMRT series, up to $69 \%$ of survivors may develop hypothyroidism (40, 115118). The median latency period has been reported in the range of 1.8-3.1 years (114-116), but the risk increases with further follow up and has been reported in excess of 10 years following treatment (114). Given this is a reversible toxicity which may significantly impact the QoL of survivors, all patients where the lower neck is irradiated should undergo indefinite biochemical screening following treatment. The National Comprehensive Cancer Network guidelines suggest testing thyroid-stimulating hormone every 6-12 months, but do not make a recommendation of duration (119). 
TABLE 6 | Selected studies reporting cranial or hypoglossal neuropathies in NPC patients treated with IMRT.

\begin{tabular}{|c|c|c|c|c|c|}
\hline Study & No. & $\begin{array}{l}\text { Median follow } \\
\text { up (range) }\end{array}$ & Incidence CN & $\begin{array}{l}\text { Incidence hypoglossal } \\
\text { neuropathy }\end{array}$ & Notes \\
\hline Lee et al. (13) & 444 & $N R^{*}$ & $1.6 \%$ & NR & IMRT lower rates than $2 \mathrm{D}(p=0.01)$ \\
\hline Zhang et al. (9) & 480 & $\begin{array}{c}3.6 y \\
(2.9-5.4 y)\end{array}$ & $3.8 \%$ & NR & $\begin{array}{l}\text { G1/2 1.7\% } \\
\text { G3/4 2.1\% } \\
\text { combined arms of study; difference } \\
\text { between NACT and CRT }\end{array}$ \\
\hline Li et al. (22) & 477 & $\begin{array}{c}5.9 y \\
(0.1-7.5 y)\end{array}$ & $3.7 \%$ & NR & $\begin{array}{l}\text { G1/2-2.3\% } \\
\text { G3/4-1.4\% } \\
\text { Combined arms of study; difference } \\
\text { between NACT and CRT }\end{array}$ \\
\hline $\begin{array}{l}\text { McDowell et al. } \\
(40)\end{array}$ & 107 & $\begin{array}{c}7.5 y \\
(4.2-11.1)\end{array}$ & $14 \%$ (late) & $13 \%$ & $\begin{array}{l}\text { G1-6\% } \\
\text { G2-4\% } \\
\text { G3-4\% }\end{array}$ \\
\hline
\end{tabular}

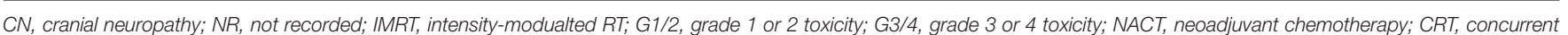
chemoradiotherapy; * not reported for IMRT cohort separately, for entire study range was 0.2-18.2 years including 2D, 3D and IMRT. **306 in IMRT arm of this study.

\section{Pituitary dysfunction}

In a meta-analysis of pituitary dysfunction in adult patients treated with cranial irradiation, the point prevalence in the pooled NPC studies was 0.74 (120). There are some limitations to this data and further research is needed to assess the true impact in the IMRT era, where the risk may be lower. One study which included basal screening reported a low rate of $1 \%$, with a median follow up of 7.5y (4.1-11.1 y) (40). However, in other populations exposed to cranial irradiation hypopituitarism may develop many years after RT (120). There is a lack of data about the true prevalence of pituitary dysfunction in NPC survivors treated with IMRT and the absolute benefit of regular screening in this group is unknown.

\section{Fatigue}

Fatigue frequently ranks highly among NPC patient-reported toxicities $(17-19,40)$. Fatigue has many potential causes in the NPC survivor, including reversible causes such as poor nutritional intake, endocrine dysfunction and emotional distress, and irreversible causes such as a high treatment-related symptom burden or the presence of distant metastases. Efforts to exclude reversible causes should be undertaken where appropriate, as fatigue has been linked to worse QoL in NPC series $(36,40)$. In the two NACT series which included the QLQ-C30, longterm fatigue was not worse in the NACT arms $(12,23)$. Other factors, such as the volume of posterior fossa irradiated may also contribute, as this has been linked to higher rates of long-term fatigue (clinician reported) assessments in both NPC (121) and non-NPC HNC studies (122).

\section{Unmet Needs}

There has been little targeted research ascertaining unmet needs in NPC survivors, although studies in the general HNC population may be broadly translatable. Unmet needs cover a variety of domains that may not have been addressed at any point through the patients' cancer journey $(123,124)$, and include physical, psychological, informational, activities of daily living, social, spiritual/existential, nutritional, dental, communication, sexual and financial needs as well as access to care (125). A variety of validated tools exist to ascertain the unmet needs of cancer patients (125-127). In non-NPC HNC populations, patients frequently identify having an unmet need. For example, in a study of HNC survivors at the Princess Margaret Hospital, $61 \%(96 / 158)$ of survivors reported at least one unmet need, and patients with worse QoL reported an increased number of unmet needs (128).

Some of these domains are better understood than others. For instance, emotional distress has been reported in patients with NPC, and its presence often correlates with lower QoL (36, $40,44)$. Fear of cancer recurrence is often cited an unmet need in HNC populations and in the study by Hong et al., frequent worry of recurrence was present in $18.5 \%$ of NPC patients (36). Workplace rehabilitation needs following treatment are also attracting increasing interest in the HNC literature. For instance in a Canadian study, which mostly included a migrant population from endemic areas, only $62 \%$ of patients who were employed prior to diagnosis and who were within working age at study enrolment $(\leq 65)$ were working (median post-RT 7.5 years) (94). One-third of those who were working also reported working fewer hours than before their diagnosis (median $14 \mathrm{~h}$, range 4-30). Patients who were working were younger, had a lower symptom burden, self-reported less changes in their frontal function and had private health benefits.

\section{Conclusion and Future Directions}

The outlook for patients with NPC has substantially improved over the last 30 years, as a consequence of concerted global research efforts and technological advancements in RT planning and delivery. Despite these improvements, many NPC patients will still develop significant long-term toxicities, negatively 
impacting their QoL. Many opportunities offer early promise for reducing the burden of toxicity including adaptive RT, response-adapted treatment planning, and the potential offered by NACT, particle and proton therapy. Early research suggests these approaches may be beneficial in reducing toxicity and improving QoL. In designing future clinical trials, the focus needs to shift from clinician-reported to patient-reported outcomes, including both toxicity and QoL assessments, which have been lacking in most large-scale prospective studies to date. While there are a number of patient-reported tools appropriate for use in NPC patients, judicious selection of tools is required to ensure all significant treatment-related toxicity is being adequately captured. Currently, there is no "all encompassing" single tool for use during the treatment and survivorship phase of NPC treatment. As we continue to move into the era of immune and targeted therapies, additional toxicities and tools may need to be incorporated. In future studies, we would

\section{REFERENCES}

1. Ng WT, Lee MC, Hung WM, Choi CW, Lee KC, Chan OS, et al. Clinical outcomes and patterns of failure after intensity-modulated radiotherapy for nasopharyngeal carcinoma. Int J Radiat Oncol Biol Phys. (2011) 79:4208. doi: 10.1016/j.ijrobp.2009.11.024

2. Lee JY, Sun JM, Oh DR, Lim SH, Goo J, Lee SH, et al. Comparison of weekly versus triweekly cisplatin delivered concurrently with radiation therapy in patients with locally advanced nasopharyngeal cancer: a multicenter randomized phase II trial (KCSG-HN10-02). Radiother Oncol. (2016) 118:244-50. doi: 10.1016/j.radonc.2015.11.030

3. Al-Sarraf M, LeBlanc M, Giri PG, Fu KK, Cooper J, Vuong T, et al. Chemoradiotherapy versus radiotherapy in patients with advanced nasopharyngeal cancer: phase III randomized intergroup study 0099. J Clin Oncol. (1998) 16:1310-7. doi: 10.1200/JCO.1998.16. 4.1310

4. Wee J, Tan EH, Tai BC, Wong HB, Leong SS, Tan T, et al. Randomized trial of radiotherapy versus concurrent chemoradiotherapy followed by adjuvant chemotherapy in patients with American joint committee on cancer/International union against cancer stage III and IV nasopharyngeal cancer of the endemic variety. J Clin Oncol. (2005) 23:6730-8. doi: 10.1200/JCO.2005.16.790

5. Chen QY, Wen YF, Guo L, Liu H, Huang PY, Mo HY, et al. Concurrent chemoradiotherapy vs radiotherapy alone in stage II nasopharyngeal carcinoma: phase III randomized trial. J Natl Cancer Inst. (2011) 103:176170. doi: 10.1093/jnci/djr432

6. Chen L, Hu CS, Chen XZ, Hu GQ, Cheng ZB, Sun Y, et al. Adjuvant chemotherapy in patients with locoregionally advanced nasopharyngeal carcinoma: long-term results of a phase 3 multicentre randomised controlled trial. Eur J Cancer. (2017) 75:150-8. doi: 10.1016/j.ejca.2017.01.002

7. Blanchard P, Lee A, Marguet S, Leclercq J, Ng WT, Ma J, et al. Chemotherapy and radiotherapy in nasopharyngeal carcinoma: an update of the MAC-NPC meta-analysis. Lancet Oncol. (2015) 16:645-55. doi: 10.1016/S1470-2045(15)70126-9

8. Baujat B, Audry H, Bourhis J, Chan AT, Onat H, Chua DT, et al. Chemotherapy in locally advanced nasopharyngeal carcinoma: an individual patient data meta-analysis of eight randomized trials and 1753 patients. Int J Radiat Oncol Biol Phys. (2006) 64:47-56. doi: 10.1016/j.ijrobp.2005.06.037

9. Zhang Y, Chen L, Hu GQ, Zhang N, Zhu XD, Yang KY, et al. Gemcitabine and cisplatin induction chemotherapy in nasopharyngeal carcinoma. $N$ Engl J Med. (2019) 381:1124-35. doi: 10.1186/s40880-019-0385-5

10. Sun Y, Li WF, Chen NY, Zhang N, Hu GQ, Xie FY, et al. Induction chemotherapy plus concurrent chemoradiotherapy versus concurrent chemoradiotherapy alone in locoregionally advanced nasopharyngeal recommend including long-term follow up, in excess of 5 years is needed to fully quantify the development of late toxicities. Where reported, results from clinical trials should focus on reporting meaningful clinical differences in QoL measures rather than statistical differences which may be of little significance to patients. Targeted research to reduce the burden of toxicities such as cognitive and hearing impairment remain areas for future research, and clarifying the unmet needs of NPC survivors in endemic and non-endemic regions provides further opportunity to improve the survivorship experience.

\section{AUTHOR CONTRIBUTIONS}

LM designed the concept of the review and wrote the first draft of the manuscript. All others contributed to the manuscript revision, read, and approved the submitted version. carcinoma: a phase 3, multicentre, randomised controlled trial. Lancet Oncol. (2016) 17:1509-20. doi: 10.1016/S1470-2045(16)30410-7

11. Cao SM, Yang Q, Guo L, Mai HQ, Mo HY, Cao KJ, et al. Neoadjuvant chemotherapy followed by concurrent chemoradiotherapy versus concurrent chemoradiotherapy alone in locoregionally advanced nasopharyngeal carcinoma: a phase III multicentre randomised controlled trial. Eur J Cancer. (2017) 75:14-23. doi: 10.1016/j.ejca.2016.12.039

12. Hui EP, Ma Bb Fau - Leung SF, Leung Sf Fau - King AD, King Ad Fau - Mo F, Mo F Fau - Kam MK, Kam Mk Fau - Yu BK, et al. Randomized phase II trial of concurrent cisplatin-radiotherapy with or without neoadjuvant docetaxel and cisplatin in advanced nasopharyngeal carcinoma. J Clin Oncol. (2009) 27:242-9. doi: 10.1200/JCO.2008.18.1545

13. Lee AW, Ng WT, Chan LL, Hung WM, Chan CC, Sze HC, et al. Evolution of treatment for nasopharyngeal cancer-success and setback in the intensity-modulated radiotherapy era. Radiother Oncol. (2014) 110:37784. doi: 10.1016/j.radonc.2014.02.003

14. Peng G, Wang T, Yang KY, Zhang S, Zhang T, Li Q, et al. A prospective, randomized study comparing outcomes and toxicities of intensitymodulated radiotherapy vs. conventional two-dimensional radiotherapy for the treatment of nasopharyngeal carcinoma. Radiother Oncol. (2012) 104:286-93. doi: 10.1016/j.radonc.2012.08.013

15. Pan XB, Huang ST, Chen KH, Jiang YM, Ma JL, Qu S, et al. Intensitymodulated radiotherapy provides better quality of life than two-dimensional conventional radiotherapy for patients with stage II nasopharyngeal carcinoma. Oncotarget. (2017) 8:46211-8. doi: 10.18632/oncotarget.17582

16. Huang TL, Chien CY, Tsai WL, Liao KC, Chou SY, Lin HC, et al. Longterm late toxicities and quality of life for survivors of nasopharyngeal carcinoma treated with intensity-modulated radiotherapy versus nonintensity-modulated radiotherapy. Head Neck. (2016) 38(Suppl. 1):E102632. doi: 10.1002/hed. 24150

17. Fang FM, Tsai WL, Chen HC, Hsu HC, Hsiung CY, Chien CY, et al. Intensitymodulated or conformal radiotherapy improves the quality of life of patients with nasopharyngeal carcinoma: comparisons of four radiotherapy techniques. Cancer. (2007) 109:313-21. doi: 10.1002/cncr.22396

18. Fang FM, Tsai WL, Lee TF, Liao KC, Chen HC, Hsu HC. Multivariate analysis of quality of life outcome for nasopharyngeal carcinoma patients after treatment. Radiother Oncol. (2010) 97:263-9. doi: 10.1016/j.radonc.2010.05.022

19. Tsai WL, Huang TL, Liao KC, Chuang HC, Lin YT, Lee TF, et al. Impact of late toxicities on quality of life for survivors of nasopharyngeal carcinoma. BMC Cancer. (2014) 14:856. doi: 10.1186/1471-2407-14-856

20. Chang ET, Adami HO. The enigmatic epidemiology of nasopharyngeal carcinoma. Cancer Epidemiol Biomarkers Prev. (2006) 15:176577. doi: 10.1158/1055-9965.EPI-06-0353 
21. Nguyen NA, Ringash J. Head and neck cancer survivorship care: a review of the current guidelines and remaining unmet needs. Curr Treat Options Oncol. (2018) 19:44. doi: 10.1007/s11864-018-0554-9

22. Li WF, Chen NY, Zhang N, Hu GQ, Xie FY, Sun $Y$, et al. Concurrent chemoradiotherapy with/without induction chemotherapy in locoregionally advanced nasopharyngeal carcinoma: long-term results of phase 3 randomized controlled trial. Int J Cancer. (2019) 145:295-305. doi: 10.1002/ijc.32099

23. Tan T, Lim WT, Fong KW, Cheah SL, Soong YL, Ang MK, et al. Concurrent chemo-radiation with or without induction gemcitabine, carboplatin, and paclitaxel: a randomized, phase $2 / 3$ trial in locally advanced nasopharyngeal carcinoma. Int J Radiat Oncol Biol Phys. (2015) 91:95260. doi: $10.1016 /$ j.ijrobp.2015.01.002

24. Hong RL, Hsiao CF, Ting LL, Ko JY, Wang CW, Chang JTC, et al. Final results of a randomized phase III trial of induction chemotherapy followed by concurrent chemoradiotherapy versus concurrent chemoradiotherapy alone in patients with stage IVA and IVB nasopharyngeal carcinomaTaiwan cooperative oncology group (TCOG) 1303 Study. Ann Oncol. (2018) 29:1972-9. doi: 10.1093/annonc/mdy249

25. Fountzilas G, Ciuleanu, Bobos M, Kalogera-Fountzila A, KalogeraFountzila A, Eleftheraki AG, et al. Induction chemotherapy followed by concomitant radiotherapy and weekly cisplatin versus the same concomitant chemoradiotherapy in patients with nasopharyngeal carcinoma: a randomized phase II study conducted by the Hellenic Cooperative Oncology Group (HeCOG) with biomarker evaluation. Ann Oncol. (2012) 23:427-35. doi: 10.1093/annonc/mdr116

26. Frikha M, Auperin A, Tao Y, Elloumi F, Toumi N, Blanchard P, et al. A randomized trial of induction docetaxel-cisplatin-5FU followed by concomitant cisplatin-RT versus concomitant cisplatin-RT in nasopharyngeal carcinoma (GORTEC 2006-02). Ann Oncol. (2018) 29:731-6. doi: 10.1093/annonc/mdx770

27. Chen L, Hu CS, Chen XZ, Hu GQ, Cheng ZB, Sun Y, et al. Concurrent chemoradiotherapy plus adjuvant chemotherapy versus concurrent chemoradiotherapy alone in patients with locoregionally advanced nasopharyngeal carcinoma: a phase 3 multicentre randomised controlled trial. Lancet Oncol. (2012) 13:163-71. doi: 10.1016/S1470-2045(11)70320-5

28. Lee AW, Tung SY, Chua DT, Ngan RK, Chappell R, Tung R, et al. Randomized trial of radiotherapy plus concurrent-adjuvant chemotherapy vs radiotherapy alone for regionally advanced nasopharyngeal carcinoma. $J$ Natl Cancer Inst. (2010) 102:1188-98. doi: 10.1093/jnci/djq287

29. Lee AWM, Tung SY, Ng WT, Lee V, Ngan RKC, Choi HCW, et al. A multicenter, phase 3, randomized trial of concurrent chemoradiotherapy plus adjuvant chemotherapy versus radiotherapy alone in patients with regionally advanced nasopharyngeal carcinoma: 10-year outcomes for efficacy and toxicity. Cancer. (2017) 123:4147-57. doi: 10.1002/cncr.30850

30. Rossi A, Molinari R, Boracchi P, Del Vecchio M, Marubini E, Nava M, et al. Adjuvant chemotherapy with vincristine, cyclophosphamide, and doxorubicin after radiotherapy in local-regional nasopharyngeal cancer: results of a 4-year multicenter randomized study. J Clin Oncol. (1988) 6:1401-10. doi: 10.1200/JCO.1988.6.9.1401

31. Chi KH, Chang Yc, Guo W-Y, Leung M-J, Shiau C-Y, Chen S-Y, et al. A phase III study of adjuvant chemotherapy in advanced nasopharyngeal carcinoma patients. Int J Radiat Oncol Biol Phys. (2002) 52:123844. doi: 10.1016/s0360-3016(01)02781-x

32. Kam MK, Leung SF, Zee B, Chau RM, Suen JJ, Mo F, et al. Prospective randomized study of intensity-modulated radiotherapy on salivary gland function in early-stage nasopharyngeal carcinoma patients. J Clin Oncol. (2007) 25:4873-9. doi: 10.1200/JCO.2007.11.5501

33. Pow EH, Kwong DL, McMillan AS, Wong MC, Sham JS, Leung LH, et al. Xerostomia and quality of life after intensity-modulated radiotherapy vs. conventional radiotherapy for early-stage nasopharyngeal carcinoma: initial report on a randomized controlled clinical trial. Int J Radiat Oncol Biol Phys. (2006) 66:981-91. doi: 10.1016/j.ijrobp.2006.06.013

34. Fang FM, Chien CY, Tsai WL, Chen HC, Hsu HC, Lui CC, et al. Quality of life and survival outcome for patients with nasopharyngeal carcinoma receiving three-dimensional conformal radiotherapy vs. intensitymodulated radiotherapy-a longitudinal study. Int J Radiat Oncol Biol Phys. (2008) 72:356-64. doi: 10.1016/j.ijrobp.2007.12.054
35. Fang FM, Huang TL, Lin YH, Chien CY, Chuang HC, Luo SD, et al. Concurrent chemoradiotherapy by simultaneously integrated boost volumetric-modulated arc therapy for nasopharyngeal carcinoma-toxicity/quality of life and survival. Head Neck. (2019) 41:1282-9. doi: 10.1002/hed.25551

36. Hong JS, Tian J, Han QF, Ni QY. Quality of life of nasopharyngeal cancer survivors in China. Curr Oncol. (2015) 22:e142-7. doi: 10.3747/co.22.2323

37. Pan XB, Huang ST, Chen KH, Jiang YM, Ma JL, Qu S, et al. Concurrent chemoradiotherapy degrades the quality of life of patients with stage II nasopharyngeal carcinoma as compared to radiotherapy. Oncotarget. (2017) 8:14029-38. doi: 10.18632/oncotarget.14932

38. Wu Y, Hu WH, Xia YF, Ma J, Liu MZ, Cui NJ. Quality of life of nasopharyngeal carcinoma survivors in Mainland China. Qual Life Res. (2007) 16:65-74. doi: 10.1007/s11136-006-9113-0

39. Tonoli S, Alterio D, Caspiani O, Bacigalupo A, Bunkheila F, Cianciulli $\mathrm{M}$, et al. Nasopharyngeal carcinoma in a low incidence European area: a prospective observational analysis from the head and neck study group of the Italian society of radiation oncology (AIRO). Strahlenther Onkol. (2016) 192:931-43. doi: 10.1007/s00066-016-1052-2

40. McDowell LJ, Rock $\mathrm{K}, \mathrm{Xu} \mathrm{W}$, Chan B, Waldron $\mathrm{J}$, Lu L, et al. Long-Term late toxicity, quality of life, and emotional distress in patients with nasopharyngeal carcinoma treated with intensity modulated radiation therapy. Int J Radiat Oncol Biol Phys. (2018) 102:34052. doi: 10.1016/j.ijrobp.2018.05.060

41. Takiar V, Ma D, Garden AS, Li J, Rosenthal DI, Beadle BM, et al. Disease control and toxicity outcomes for T4 carcinoma of the nasopharynx treated with intensity-modulated radiotherapy. Head Neck. (2016) 38(Suppl. 1):E925-33. doi: 10.1002/hed.24128

42. Lastrucci L, Bertocci S, Bini V, Borghesi S, De Majo R, Rampini $\mathrm{A}$, et al. Late toxicity, evolving radiotherapy techniques, and quality of life in nasopharyngeal carcinoma. Radiol Med. (2017) 122:3038. doi: 10.1007/s11547-016-0722-6

43. Talmi YP, Horowitz Z, Bedrin L, Wolf M, Chaushu G, Kronenberg J, et al. Quality of life of nasopharyngeal carcinoma patients. Cancer. (2002) 94:1012-7. doi: $10.1002 / \mathrm{cncr} .10342$

44. Ghiggia A, Castelli L, Riva G, Tesio V, Provenzano E, Ravera M, et al. Psychological distress and coping in nasopharyngeal cancer: an explorative study in Western Europe. Psychol Health Med. (2017) 22:44961. doi: 10.1080/13548506.2016.1220600

45. Yee D, Hanson J, Lau H, Siever J, Gluck S. Treatment of nasopharyngeal carcinoma in the modern era: analysis of outcomes and toxicity from a single center in a nonendemic area. Cancer J. (2006) 12:147-54. Available online at: https://journals.lww.com/journalppo/Abstract/2006/ 03000/Treatment_of_Nasopharyngeal_Carcinoma_in_the.11.aspx

46. Fromme EK, Eilers KM, Mori M, Hsieh YC, Beer TM. How accurate is clinician reporting of chemotherapy adverse effects? A comparison with patient-reported symptoms from the quality-of-life questionnaire C30. J Clin Oncol. (2004) 22:3485-90. doi: 10.1200/JCO.2004.03.025

47. Vogelzang NJ, Breitbart W, Cella D, Curt GA, Groopman JE, Horning SJ, et al. Patient, caregiver, and oncologist perceptions of cancer-related fatigue: results of a tripart assessment survey. The fatigue coalition. Semin Hematol. (1997) 34(3 Suppl. 2):4-12.

48. Ingham J, Portenoy R. The measurement of pain and other symptoms. In: Doyle DH, GWC, MacDonald N, editor. Oxford Textboo of Palliative Medicine. Oxford: Oxford University Press, (1998). p. 203-19.

49. Patrick DL, Ferketich SL, Frame PS, Harris JJ, Hendricks CB, Levin B, et al. National institutes of health state-of-the-science conference statement: symptom management in cancer: pain, depression, and fatigue, july 15-17, 2002. J Natl Cancer Inst. (2003) 95:1110-7. doi: 10.1093/jnci/djg014

50. Aaronson NK, Ahmedzai S, Bergman B, Bullinger M, Cull A, Duez NJ, et al. The European organization for research and treatment of cancer QLQ-C30: a quality-of-life instrument for use in international clinical trials in oncology. J Natl Cancer Inst. (1993) 85:365-76.

51. Bjordal K, Hammerlid E, Ahlner-Elmqvist M, de Graeff A, Boysen M, Evensen JF, et al. Quality of life in head and neck cancer patients: validation of the European organization for research and treatment of cancer quality of life questionnaire-H\&N35. J Clin Oncol. (1999) 17:100819. doi: 10.1200/JCO.1999.17.3.1008 
52. Cocks K, King MT, Velikova G, Fayers PM, Brown JM. Quality, interpretation and presentation of European organisation for research and treatment of cancer quality of life questionnaire core 30 data in randomised controlled trials. Eur J Cancer. (2008) 44:1793-8. doi: 10.1016/j.ejca.2008.05.008

53. Osoba D, Bezjak A, Brundage M, Zee B, Tu D, Pater J, et al. Analysis and interpretation of health-related quality-of-life data from clinical trials: basic approach of the National cancer institute of canada clinical trials group. Eur J Cancer. (2005) 41:280-7. doi: 10.1016/j.ejca.2004.10.017

54. Cocks K, King MT, Velikova G, Martyn St-James M, Fayers PM, Brown JM. Evidence-based guidelines for determination of sample size and interpretation of the European organisation for the research and treatment of cancer quality of life questionnaire core 30. J Clin Oncol. (2011) 29:8996. doi: 10.1200/JCO.2010.28.0107

55. Lim AM, Corry J, Collins M, Peters L, Hicks RJ, D'Costa I, et al. A phase II study of induction carboplatin and gemcitabine followed by chemoradiotherapy for the treatment of locally advanced nasopharyngeal carcinoma. Oral Oncol. (2013) 49:468-74. doi: 10.1016/j.oraloncology.2012.12.012

56. Rischin D, Corry J, Smith J, Stewart J, Hughes P, Peters L. Excellent disease control and survival in patients with advanced nasopharyngeal cancer treated with chemoradiation. J Clin Oncol. (2002) 20:184552. doi: 10.1200/JCO.2002.07.011

57. Liu F, Jin T, Liu LA-O, Xiang Z, Yan R, Yang H. The role of concurrent chemotherapy for stage II nasopharyngeal carcinoma in the intensitymodulated radiotherapy era: a systematic review and meta-analysis. PLoS ONE. (2018) 13:e0194733. doi: 10.1371/journal.pone.0194733

58. Ou X, Shen C, Kong L, Wang X, Ding J, Gao Y, et al. Treatment outcome of nasopharyngeal carcinoma with retropharyngeal lymph nodes metastasis only and the feasibility of elective neck irradiation. Oral Oncol. (2012) 48:1045-50. doi: 10.1016/j.oraloncology.2012.04.011

59. Yi J, Zhao C, Chen X, Huang X, Gao L, Luo JW, et al. The value of adding chemotherapy to intensity modulated radiation therapy for stage II nasopharyngeal carcinoma: a multicenter phase 2 study. Int J Radiat Oncol Biol Phys. (2015) 93:S128. doi: 10.1016/j.ijrobp.2015.07.305

60. Noronha V, Joshi A, Patil VM, Agarwal J, Ghosh-Laskar S, Budrukkar A, et al. Once-a-week versus once-every-3-weeks cisplatin chemoradiation for locally advanced head and neck cancer: a phase III randomized noninferiority trial. J Clin Oncol. (2018) 36:1064-72. doi: 10.1200/JCO.2017.74.9457

61. Bauml JM, Vinnakota R, Anna Park YH, Bates SE, Fojo T, Aggarwal C, et al. Cisplatin every 3 weeks versus weekly with definitive concurrent radiotherapy for squamous cell carcinoma of the head and neck. $J$ Natl Cancer Inst. (2019) 111:490-7. doi: 10.1093/jnci/djy133

62. Lu SH, Cheng JC, Kuo SH, Lee JJ, Chen LH, Wu JK, et al. Volumetric modulated arc therapy for nasopharyngeal carcinoma: a dosimetric comparison with tomotherapy and step-and-shoot IMRT. Radiother Oncol. (2012) 104:324-30. doi: 10.1016/j.radonc.2011.11.017

63. Yang H, Hu W, Wang W, Chen P, Ding W, Luo W. Replanning during intensity modulated radiation therapy improved quality of life in patients with nasopharyngeal carcinoma. Int J Radiat Oncol Biol Phys. (2013) 85:e4754. doi: 10.1016/j.ijrobp.2012.09.033

64. Yang H, Chen X, Lin S, Rong J, Yang M, Wen Q, et al. Treatment outcomes after reduction of the target volume of intensity-modulated radiotherapy following induction chemotherapy in patients with locoregionally advanced nasopharyngeal carcinoma: a prospective, multi-center, randomized clinical trial. Radiother Oncol. (2018) 126:37-42. doi: 10.1016/j.radonc.2017. 07.020

65. Xue $\mathrm{F}, \mathrm{Hu} \mathrm{C}, \mathrm{He} \mathrm{X}$. Induction chemotherapy followed by intensitymodulated radiotherapy with reduced gross tumor volume delineation for stage T3-4 nasopharyngeal carcinoma. Oncol Targets Ther. (2017) 10:332936. doi: 10.2147/OTT.S140420

66. Xiang L, Wu J, Yang H, Lin S, Zhang J, Wen Q, et al. Four-year outcome after reduction of the target volume of intensity modulated radiotherapy following induction chemotherapy in locoregionally advanced nasopharyngeal carcinoma: a phase III, multicentre, randomised controlled trial. Int J Radiat Oncol Biol Phys. (2019) 105:S18. doi: 10.1016/j.ijrobp.2019.06.414

67. Wang L, Wu Z, Xie D, Zeng R, Cheng W, Hu J, et al. Reduction of target volume and the corresponding dose for the tumor regression field after induction chemotherapy in locoregionally advanced nasopharyngeal carcinoma. Cancer Res Treat. (2019) 51:685-95. doi: 10.4143/crt.2018.250

68. Zhao C, Miao JJ, Hua YJ, Wang L, Han F, Lu LX, et al. Locoregional control and mild late toxicity after reducing target volumes and radiation doses in patients with locoregionally advanced nasopharyngeal carcinoma treated with induction chemotherapy (IC) followed by concurrent chemoradiotherapy: 10-year results of a phase 2 study. Int J Radiat Oncol Biol Phys. (2019) 104:836-44. doi: 10.1016/j.ijrobp.2019.03.043

69. Wang X, Wang Y, Jiang S, Zhao J, Wang P, Zhang X, et al. Safety and effectiveness of de-escalated radiation dose in T1-3 nasopharyngeal carcinoma: a propensity matched analysis. J Cancer. (2019) 10:505764. doi: 10.7150/jca.33303

70. Lu T, Xie X, Guo Q, Zhan S, Lin C, Lin S, et al. Prognosis of nasopharyngeal carcinoma with insufficient radical dose to the primary site in the intensity-modulated radiotherapy era. Head Neck. (2019) 41:351624. doi: 10.1002/hed.25865

71. Zhang F, Cheng YK, Li WF, Guo R, Chen L, Sun Y, et al. Investigation of the feasibility of elective irradiation to neck level Ib using intensity-modulated radiotherapy for patients with nasopharyngeal carcinoma: a retrospective analysis. BMC Cancer. (2015) 15:709. doi: 10.1186/s12885-015-1669-z

72. Murdoch-Kinch CA, Kim HM, Vineberg KA, Ship JA, Eisbruch A. Doseeffect relationships for the submandibular salivary glands and implications for their sparing by intensity modulated radiotherapy. Int J Radiat Oncol Biol Phys. (2008) 72:373-82. doi: 10.1016/j.ijrobp.2007.12.033

73. Li M, Huang XG, Yang ZN, Lu JY, Zhan YZ, Xie WJ, et al. Effects of omitting elective neck irradiation to nodal level IB in nasopharyngeal carcinoma patients with negative level IB lymph nodes treated by intensity-modulated radiotherapy: a phase 2 study. Br J Radiol. (2016) 89:20150621. doi: 10.1259/bjr.20150621

74. Gao Y, Zhu G, Lu J, Ying H, Kong L, Wu Y, et al. Is elective irradiation to the lower neck necessary for N0 nasopharyngeal carcinoma? Int J Radiat Oncol Biol Phys. (2010) 77:1397-402. doi: 10.1016/j.ijrobp.2009.06.062

75. Steneker M, Lomax A, Schneider U. Intensity modulated photon and proton therapy for the treatment of head and neck tumors. Radiother Oncol. (2006) 80:263-7. doi: 10.1016/j.radonc.2006.07.025

76. Cozzi L, Fogliata A, Lomax A, Bolsi A. A treatment planning comparison of $3 \mathrm{D}$ conformal therapy, intensity modulated photon therapy and proton therapy for treatment of advanced head and neck tumours. Radiother Oncol. (2001) 61:287-97. doi: 10.1016/S0167-8140(01)00403-0

77. Taheri-Kadkhoda Z, Bjork-Eriksson T, Nill S, Wilkens JJ, Oelfke U, Johansson $\mathrm{KA}$, et al. Intensity-modulated radiotherapy of nasopharyngeal carcinoma: a comparative treatment planning study of photons and protons. Radiat Oncol. (2008) 3:4. doi: 10.1186/1748-717X-3-4

78. Widesott L, Pierelli A, Fiorino C, Dell'oca I, Broggi S, Cattaneo GM, et al. Intensity-modulated proton therapy versus helical tomotherapy in nasopharynx cancer: planning comparison and NTCP evaluation. Int $J$ Radiat Oncol Biol Phys. (2008) 72:589-96. doi: 10.1016/j.ijrobp.2008.05.065

79. Lewis GD, Holliday EB, Kocak-Uzel E, Hernandez M, Garden AS, Rosenthal DI, et al. Intensity-modulated proton therapy for nasopharyngeal carcinoma: decreased radiation dose to normal structures and encouraging clinical outcomes. Head Neck. (2016) 38(Suppl. 1):E1886-95. doi: 10.1002/hed.24341

80. Holliday EB, Garden AS, Rosenthal DI, Fuller CD, Morrison WH, Gunn GB, et al. Proton therapy reduces treatment-related toxicities for patients with nasopharyngeal cancer: a case-match control study of intensity-modulated proton therapy and intensity-modulated photon therapy. Int J Part Ther. (2015) 2:19-28. doi: 10.14338/IJPT-15-00011.1

81. Chan A, Adams JA, Weyman E, Parambi R, Goldsmith T, Holman A, et al. A phase II trial of proton radiation therapy with chemotherapy for nasopharyngeal carcinoma. Int J Radiat Oncol Biol Phys. (2012) 84:S1512. doi: 10.1016/j.ijrobp.2012.07.391

82. Chan AW, Liebsch LJ, Deschler DG, Adams JA, Vrishali LV, McIntyre JF, et al. Proton radiotherapy for T4 nasopharyngeal carcinoma. J Clin Oncol. (2004) 22(Suppl. 14):5574. doi: 10.1200/jco.2004.22.14_suppl.5574

83. van der Veen J, Gulyban A, Nuyts S. Interobserver variability in delineation of target volumes in head and neck cancer. Radiother Oncol. (2019) 137:915. doi: 10.1016/j.radonc.2019.04.006

84. Weiss E, Hess CF. The impact of gross tumor volume (GTV) and clinical target volume (CTV) definition on the total accuracy in radiotherapy 
theoretical aspects and practical experiences. Strahlenther Onkol. (2003) 179:21-30. doi: 10.1007/s00066-003-0976-5

85. Liu X, Le QT, Ma J. Focus on the number of radiation oncology trials or on clinical relevance-reply. JAMA Oncol. (2018) 4:17912. doi: 10.1001/jamaoncol.2018.5105

86. Peters LJ, O'Sullivan B, Giralt J, Fitzgerald TJ, Trotti A, Bernier J, et al. Critical impact of radiotherapy protocol compliance and quality in the treatment of advanced head and neck cancer: results from TROG 02.02. J Clin Oncol. (2010) 28:2996-3001. doi: 10.1200/JCO.2009.27.4498

87. Lee AW, Ng WT, Pan JJ, Poh SS, Ahn YC, AlHussain H, et al. International guideline for the delineation of the clinical target volumes (CTV) for nasopharyngeal carcinoma. Radiother Oncol. (2018) 126:2536. doi: 10.1016/j.radonc.2017.10.032

88. Lee AW, Ng WT, Pan JJ, Chiang CL, Poh SS, Choi HC, et al. International guideline on dose prioritization and acceptance criteria in radiation therapy planning for nasopharyngeal carcinoma. Int J Radiat Oncol Biol Phys. (2019) 105:567-80. doi: 10.1016/j.ijrobp.2019.09.030

89. Wuthrick EJ, Zhang Q, Machtay M, Rosenthal DI, Nguyen-Tan PF, Fortin A, et al. Institutional clinical trial accrual volume and survival of patients with head and neck cancer. J Clin Oncol. (2015) 33:15664. doi: 10.1200/JCO.2014.56.5218

90. Torabi SJ, Benchetrit L, Kuo Yu P, Cheraghlou S, Savoca EL, Tate JP, et al. Prognostic case volume thresholds in patients with head and neck squamous cell carcinoma. JAMA Otolaryngol Head Neck Surg. (2019) 145:708-15. doi: 10.1001/jamaoto.2019.1187

91. Amarasena I, Herschtal A, D'Costa I, Fua T, Tiong A, Geddes V, et al. Outcomes of routine intensity modulated radiation therapy quality assurance in a large head and neck cancer center. Int $J$ Radiat Oncol Biol Phys. (2017) 98:541-6. doi: 10.1016/j.ijrobp.2017. 02.215

92. McDowell L, Corry J. Radiation therapy quality assurance in head and neck radiotherapy - moving forward. Oral Oncol. (2019) 88:1805. doi: 10.1016/j.oraloncology.2018.11.014

93. McDowell LJ, Corry J. A call to arms: radiation therapy quality assurance in the next generation of clinical trials. Int J Radiat Oncol Biol Phys. (2018) 102:1590-1. doi: 10.1016/j.ijrobp.2018.07.2001

94. So N, McDowell LJ, Lu L, Xu W, Rock K, Waldron J, et al. The prevalence and determinants of return to work in nasopharyngeal carcinoma survivors. Int $J$ Radiat Oncol Biol Phys. (2019) 106:134-45. doi: 10.1016/j.ijrobp.2019.09.008

95. Ronis DL, Duffy SA, Fowler KE, Khan MJ, Terrell JE. Changes in quality of life over 1 year in patients with head and neck cancer. Arch Otolaryngol Head Neck Surg. (2008) 134:241-8. doi: 10.1001/archoto.2007.43

96. Howren MB, Christensen AJ, Karnell LH, Funk GF. Health-related quality of life in head and neck cancer survivors: impact of pretreatment depressive symptoms. Health Psychol. (2010) 29:65-71. doi: 10.1037/a0017788

97. Hammerlid E, Silander E, Hornestam L, Sullivan M. Healthrelated quality of life three years after diagnosis of head and neck cancer-a longitudinal study. Head Neck. (2001) 23:11325. doi: 10.1002/1097-0347(200102)23:2<113::aid-hed1006>3.0.co;2-w

98. Barber B, Dergousoff J, Nesbitt M, Mitchell N, Harris J, O'Connell D, et al. Depression as a predictor of postoperative functional performance status (PFPS) and treatment adherence in head and neck cancer patients: a prospective study. J Otolaryngol Head Neck Surg. (2015) 44:38. doi: 10.1186/s40463-015-0092-4

99. Tang Y, Luo D, Rong X, Shi X, Peng Y. Psychological disorders, cognitive dysfunction and quality of life in nasopharyngeal carcinoma patients with radiation-induced brain injury. PLoS ONE. (2012) 7:e36529. doi: 10.1371/journal.pone.0036529

100. Lue BH, Huang TS, Chen HJ. Physical distress, emotional status, and quality of life in patients with nasopharyngeal cancer complicated by postradiotherapy endocrinopathy. Int J Radiat Oncol Biol Phys. (2008) 70:2834. doi: 10.1016/j.ijrobp.2007.06.053

101. Wang X, Lv Y, Li W, Gan C, Chen H, Liu Y, et al. Correlation between psychosocial distress and quality of life in patients with nasopharyngeal carcinoma following radiotherapy. J Oncol. (2018) 2018:3625302. doi: 10.1155/2018/3625302

102. Yu CL, Fielding R, Chan CL, Sham JS. Chinese nasopharyngeal carcinoma patients treated with radiotherapy: association between satisfaction with information provided and quality of life. Cancer. (2001) 92:212635. doi: 10.1002/cncr.1554

103. Kong L, Lu JJ, Liss AL, Hu C, Guo X, Wu Y, et al. Radiation-induced cranial nerve palsy: a cross-sectional study of nasopharyngeal cancer patients after definitive radiotherapy. Int J Radiat Oncol Biol Phys. (2011) 79:14217. doi: 10.1016/j.ijrobp.2010.01.002

104. Luk YS, Shum JS, Sze HC, Chan LL, Ng WT, Lee AW. Predictive factors and radiological features of radiation-induced cranial nerve palsy in patients with nasopharyngeal carcinoma following radical radiotherapy. Oral Oncol. (2013) 49:49-54. doi: 10.1016/j.oraloncology.2012.07.011

105. Rong X, Tang Y, Chen M, Lu K, Peng Y. Radiation-induced cranial neuropathy in patients with nasopharyngeal carcinoma. A follow-up study. Strahlenther Onkol. (2012) 188:282-6. doi: 10.1007/s00066-011-0047-2

106. Chow JCH, Cheung KM, Au KH, Zee BCY, Lee J, Ngan RKC, et al. Radiation-induced hypoglossal nerve palsy after definitive radiotherapy for nasopharyngeal carcinoma: clinical predictors and dose-toxicity relationship. Radiother Oncol. (2019) 138:93-8. doi: 10.1016/j.ijrobp.2019.06.290

107. McDowell LJ, Jacobson MC, Levin W. High-dose intravenous steroid regimen for radiation-induced hypoglossal nerve palsy. Head Neck. (2017) 39:E23-8. doi: 10.1002/hed.24600

108. Cheung MC, Chan AS, Law SC, Chan JH, Tse VK. Impact of radionecrosis on cognitive dysfunction in patients after radiotherapy for nasopharyngeal carcinoma. Cancer. (2003) 97:2019-26. doi: 10.1002/cncr.11295

109. Kiang A, Weinberg VK, Cheung KH, Shugard E, Chen J, Quivey $\mathrm{JM}$, et al. Long-term disease-specific and cognitive quality of life after intensity-modulated radiation therapy: a cross-sectional survey of nasopharyngeal carcinoma survivors. Radiat Oncol. (2016) 11:127. doi: 10.1186/s13014-016-0704-9

110. Hsiao KY, Yeh SA, Chang CC, Tsai PC, Wu JM, Gau JS. Cognitive function before and after intensity-modulated radiation therapy in patients with nasopharyngeal carcinoma: a prospective study. Int J Radiat Oncol Biol Phys. (2010) 77:722-6. doi: 10.1016/j.ijrobp.2009.06.080

111. Mo YL, Li L, Qin L, Zhu XD, Qu S, Liang X, et al. Cognitive function, mood, and sleep quality in patients treated with intensity-modulated radiation therapy for nasopharyngeal cancer: a prospective study. Psycho Oncol. (2014) 23:1185-91. doi: 10.1002/pon.3542

112. McDowell LJ, Ringash J, Xu W, Chan B, Lu L, Waldron J, et al. A cross sectional study in cognitive and neurobehavioral impairment in long-term nasopharyngeal cancer survivors treated with intensity-modulated radiotherapy. Radiother Oncol. (2019) 131:179-85. doi: 10.1016/j.radonc.2018.09.012

113. Ongnok B, Chattipakorn N, Chattipakorn SC. Doxorubicin and cisplatin induced cognitive impairment: the possible mechanisms and interventions. Exp Neurol. (2020) 324:113118. doi: 10.1016/j.expneurol.2019. 113118

114. Fan CY, Lin CS, Chao HL, Huang WY, Su YF, Lin KT, et al. Risk of hypothyroidism among patients with nasopharyngeal carcinoma treated with radiation therapy: a population-based cohort study. Radiother Oncol. (2017) 123:394-400. doi: 10.1016/j.radonc.2017.04.025

115. Lertbutsayanukul C, Kitpanit S, Prayongrat A, Kannarunimit D, Netsawang B, Chakkabat C. Validation of previously reported predictors for radiationinduced hypothyroidism in nasopharyngeal cancer patients treated with intensity-modulated radiation therapy, a post hoc analysis from a phase III randomized trial. J Radiat Res. (2018) 59:446-55. doi: 10.1093/jrr/rry036

116. Sommat K, Ong WS, Hussain A, Soong YL, Tan T, Wee J, et al. Thyroid $\mathrm{V} 40$ predicts primary hypothyroidism after intensity modulated radiation therapy for nasopharyngeal carcinoma. Int J Radiat Oncol Biol Phys. (2017) 98:574-80. doi: 10.1016/j.ijrobp.2017.03.007

117. Huang S, Wang $\mathrm{X}, \mathrm{Hu} \mathrm{C}$, Ying $\mathrm{H}$. Hypothalamic-pituitary-thyroid dysfunction induced by intensity-modulated radiotherapy (IMRT) for adult patients with nasopharyngeal carcinoma. Med Oncol. (2013) 30:710. doi: 10.1007/s12032-013-0710-9

118. Huang CL, Tan HW, Guo R, Zhang Y, Peng H, Peng L, et al. Thyroid dose-volume thresholds for the risk of radiation-related hypothyroidism in nasopharyngeal carcinoma treated with intensitymodulated radiotherapy-A single-institution study. Cancer Med. (2019) 8:6887-93. doi: $10.1002 / \mathrm{cam} 4.2574$ 
119. National Comprehensive Cancer Network. Head and Neck Cancers. (2019). Available online at: https://www.nccn.org/professionals/physician_gls/pdf/ head-and-neck.pdf

120. Appelman-Dijkstra NM, Kokshoorn NE, Dekkers OM, Neelis KJ, Biermasz NR, Romijn JA, et al. Pituitary dysfunction in adult patients after cranial radiotherapy: systematic review and meta-analysis. J Clin Endocrinol Metab. (2011) 96:2330-40. doi: 10.1210/jc.2011-0306

121. Powell C, Schick U, Morden JP, Gulliford SL, Miah AB, Bhide S, et al. Fatigue during chemoradiotherapy for nasopharyngeal cancer and its relationship to radiation dose distribution in the brain. Radiother Oncol. (2014) 110:41621. doi: 10.1016/j.radonc.2013.06.042

122. Gulliford SL, Miah AB, Brennan S, McQuaid D, Clark CH, Partridge $\mathrm{M}$, et al. Dosimetric explanations of fatigue in head and neck radiotherapy: an analysis from the PARSPORT phase III trial. Radiother Oncol. (2012) 104:205-12. doi: 10.1016/j.radonc.2012. 07.005

123. Harrison JD, Young JM, Price MA, Butow PN, Solomon MJ. What are the unmet supportive care needs of people with cancer? A systematic review. Support Care Cancer. (2009) 17:1117-28. doi: 10.1007/s00520-0090615-5

124. Osse BH, Vernooij-Dassen Mj, de Vree BP, Schade E, Grol RP. Assessment of the need for palliative care as perceived by individual cancer patients and their families: a review of instruments for improving patient participation in palliative care. Cancer. (2000) 88:900-11. doi: 10.1002/(sici)10970142(20000215)88:4<900::aid-cncr22>3.0.co;2-2
125. Shunmugasundaram C, Rutherford C, Butow PN, Sundaresan P, Dhillon HM. Content comparison of unmet needs self-report measures used in patients with head and neck cancer: a systematic review. Psychooncology. (2019) 28:2295-306. doi: 10.1002/pon.5257

126. Ringash J, Bernstein LJ, Devins G, Dunphy C, Giuliani M, Martino R, et al. Head and neck cancer survivorship: learning the needs, meeting the needs. Semin Radiat Oncol. (2018) 28:64-74. doi: 10.1016/j.semradonc.2017.08.008

127. Rogers SN, El-Sheikha J, Lowe D. The development of a Patients Concerns Inventory (PCI) to help reveal patients concerns in the head and neck clinic. Oral Oncol. (2009) 45:555-61. doi: 10.1016/j.oraloncology.2008.09.004

128. Giuliani M, McQuestion M, Jones J, Papadakos J, Le LW, Alkazaz N, et al. Prevalence and nature of survivorship needs in patients with head and neck cancer. Head Neck. (2016) 38:1097-103. doi: 10.1002/hed.24411

Conflict of Interest: The authors declare that the research was conducted in the absence of any commercial or financial relationships that could be construed as a potential conflict of interest.

Copyright (c) 2020 McDowell, Corry, Ringash and Rischin. This is an open-access article distributed under the terms of the Creative Commons Attribution License (CC $B Y)$. The use, distribution or reproduction in other forums is permitted, provided the original author(s) and the copyright owner(s) are credited and that the original publication in this journal is cited, in accordance with accepted academic practice. No use, distribution or reproduction is permitted which does not comply with these terms. 